$1-1-2009$

\title{
Synthesis and Evaluation of Some Steroidal Oximes as Cytotoxic Agents: Structure/Activity Studies (I)
}

\author{
Jianguo Cui \\ Guangxi Teachers Education University \\ Lei Fan \\ Cleveland State University \\ Li Liang Huang \\ Guangxi Teachers Education University \\ Hong Li Liu \\ Cleveland State University \\ Aimin Zhou \\ Cleveland State University, A.ZHOU@csuohio.edu
}

Follow this and additional works at: https://engagedscholarship.csuohio.edu/scichem_facpub

Part of the Chemistry Commons

How does access to this work benefit you? Let us know!

\section{Recommended Citation}

Cui, Jianguo; Fan, Lei; Huang, Li Liang; Liu, Hong Li; and Zhou, Aimin, "Synthesis and Evaluation of Some Steroidal Oximes as Cytotoxic Agents: Structure/Activity Studies (I)" (2009). Chemistry Faculty Publications. 417.

https://engagedscholarship.csuohio.edu/scichem_facpub/417

This Article is brought to you for free and open access by the Chemistry Department at EngagedScholarship@CSU. It has been accepted for inclusion in Chemistry Faculty Publications by an authorized administrator of EngagedScholarship@CSU. For more information, please contact library.es@csuohio.edu. 


\title{
Synthesis and evaluation of some steroidal oximes as cytotoxic agents: Structure/activity studies (I)
}

\author{
Jian-Guo Cui , Lei Fan , Li-Liang Huang , Hong-Li Liu , Ai-Min Zhou
}

\section{Introduction}

A variety of steroids with unusual and interesting structures have been isolated from marine sponges recently [1-3]. Among these steroidal compounds, marine steroids with oxime groups have been reported rarely. Two steroidal oximes, (6E)-hydroximino-24-ethylcholest-4-en-3-one and (6E)-hydroximinocholest-4-en-3-one, were isolated from Cinachyrella alloclada and C. apion [4] in 1997, and another steroidal oxime, (3E)-hydroximinocholest-4-en-6-one, was isolated from marine sponge Cinachyrella australiensis of South China Sea [5] in 2005. The structures of the three compounds are shown in Fig. 1. Studies have revealed that these steroids exert interesting biological activities. For example, the compound 3 displays antiviral function to hepatitis virus (Hep G2) in vitro [5] and the compound 2 exerts cytotoxic activities against several types of cancer cells such as P-388 (murine leukemia), A-549 (human lung carcinoma), HT-29 (human colorectal adenocarcinoma) and MEL-28 (human myeloma) tumor cells [6].

In recent years, several 6-hydroximinosteroid analogues have been synthesized and evaluated for their cytotoxicity [7-9]. Interestingly, studies have revealed that the cytotoxicity of these compounds against cancer cells is dependent on the location of the hydroximino group on the steroidal nucleus. The parental steroids with a hydroximino group located at a different position show a remarkable difference in their cytotoxicities, suggesting the importance of a side chain location on a steroid compound in its biological functions. In this report we present more evidence that the cytotoxicity of steroidal oximes we synthesized is not only dependent on the location of a hydroximino group but also the type of a side chain at position 17 on the parental steroid. Our results may provide useful information for the design of chemotherapeutic drugs. 
<smiles>CCC(C)C(C)CCC(C)C1CCC2C3C/C(=N\O)C4=CC(=O)CCC4(C)C3CCC12C</smiles>

1<smiles>CC(C)CCCC(C)C1CCC2C3C/C(=N\O)C4=CC(=O)CCC4(C)C3CCC12C</smiles>

2<smiles>CC(C)CCCC1CCC2C3CC(=O)C4=C/C(=N/O)CCC4(C)C3CCC12C</smiles>

3

Fig. 1 - Natural steroidal oximes. (1) (6E)-hydroximino-24-ethylcholest-4-en-3-one; (2) (6E)-hydroximinocholest-4-en-3-one; (3) (3E)-hydroximinocholest-4-en-6-one.

\section{Results and discussion}

Chemistry

To determine the effect of the type of a side chain and the hydroximino position on the biological role of a steroidal compound, we have synthesized several analogues of steroidal oximes with the variation of the side chain at position 17 and the hydroximino group on the A ring or $\mathrm{B}$ ring by using cholesterol, stigmasterol and $\beta$-sitosterol.

\section{Synthesis of analogues of}

(3E)-hydroximino-4-en-6-one steroids (Scheme 1)

The steroidal oxime 3 and its analogues, with a hydroxymino group on the A ring, were synthesized in two steps according to the sequence shown in Scheme 1. First, the compound $4 \mathrm{a}$ was converted to the corresponding 4-en-3,6-dione (5a) via oxidation with pyridinium chlorochromate (PCC) in $\mathrm{CH}_{2} \mathrm{Cl}_{2}$. Next, the oxime 3 was produced in a yield of $87 \%$ by the reaction of 5 a with hydroxylamine hydrochloride in ethanol in the presence of NaOAc. At the same time, the compound 2 was obtained as a byproduct in 3\% yield. The structure of 3 and 2 was confirmed by analysis of the proton and carbon NMR chemical shifts at C-2 and C-7. Resonances showing H-2 at $3.095 \mathrm{ppm}(\mathrm{dd}, J=18.0$ and $3.8 \mathrm{~Hz}$ ) and $C-3$ at $155.808 \mathrm{ppm}$ demonstrated a position of 3-hydroxymino in 3 , while the chemical shifts found for $7-\beta \mathrm{H}$ and C-6 at $3.437 \mathrm{ppm}(1 \mathrm{H}, \mathrm{dd}$, $J=15.9$ and $4.6 \mathrm{~Hz}$ ) and $149.173 \mathrm{ppm}$, respectively were indicative of the E-configuration of 6-hydroxymino in 2.
Synthesis of analogues of

(6E)-hydroximino-4-en-3-one steroids (Scheme 2)

Seven steps were needed to synthesize compound 1 as reported in Ref. [4]. Here, we introduce a new synthetic method for the steroidal oxime compounds 1, 2 and 10 with higher overall yields and fewer synthetic steps [10].

The cholest-4-en-3,6-dione (5a) was converted to $8 \mathrm{a}$ by selective reduction using $\mathrm{NaBH}_{4}$ in the presence of $\mathrm{CoCl}_{2}$ according to the synthetic method we developed. The structure of $8 \mathrm{a}$ was confirmed by comparing IR and ${ }^{1} \mathrm{H}$ NMR spectra with those of the analogous compound that was analyzed previously. The oxime $9 \mathrm{a}$ was generated by the reaction of $8 \mathrm{a}$ with hydroxylamine hydrochloride in ethanol in the presence of NaOAc. At the same time, Z-isomer of 9a was yielded in the reaction with a lower yield (3\%). The oxidation of 9a with a Jones' reagent in acetone produced the compound 2 .

\section{Synthesis of analogues of}

(7E)-hydroximino-5-en-3-ol steroids (Scheme 3)

We designed and synthesized a series of analogues of (7E)hydroximino-5-en-3-ol steroids. These compounds have a hydroxyimino group at $\mathrm{C}-7$ on the $\mathrm{B}$ ring. The following steps were used to synthesize these compounds. First, the $3 \beta$ hydroxy group of $4 \mathrm{a}$ was protected by forming the acetic ester (11a), which was then converted to a 5-ene-7-one 12a by oxidation with $\mathrm{CrO}_{3}$ in pyridine and dichloromethane for $25 \mathrm{~h}$ at ambient temperature. The yield of the product was about $71 \%$. The hydrolysis of $12 \mathrm{a}$ with alcoholic $\mathrm{K}_{2} \mathrm{CO}_{3}$ obtained the compound $13 \mathrm{a}$ in a yield of $73 \%$. Final oximination of $12 \mathrm{a}$ and $13 \mathrm{a}$

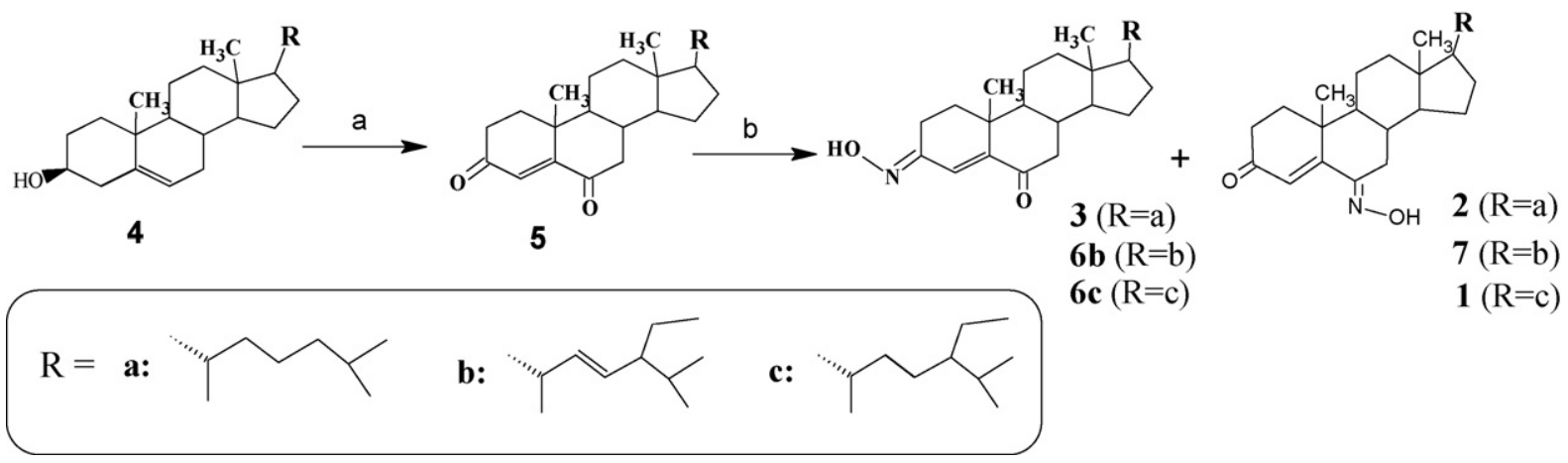



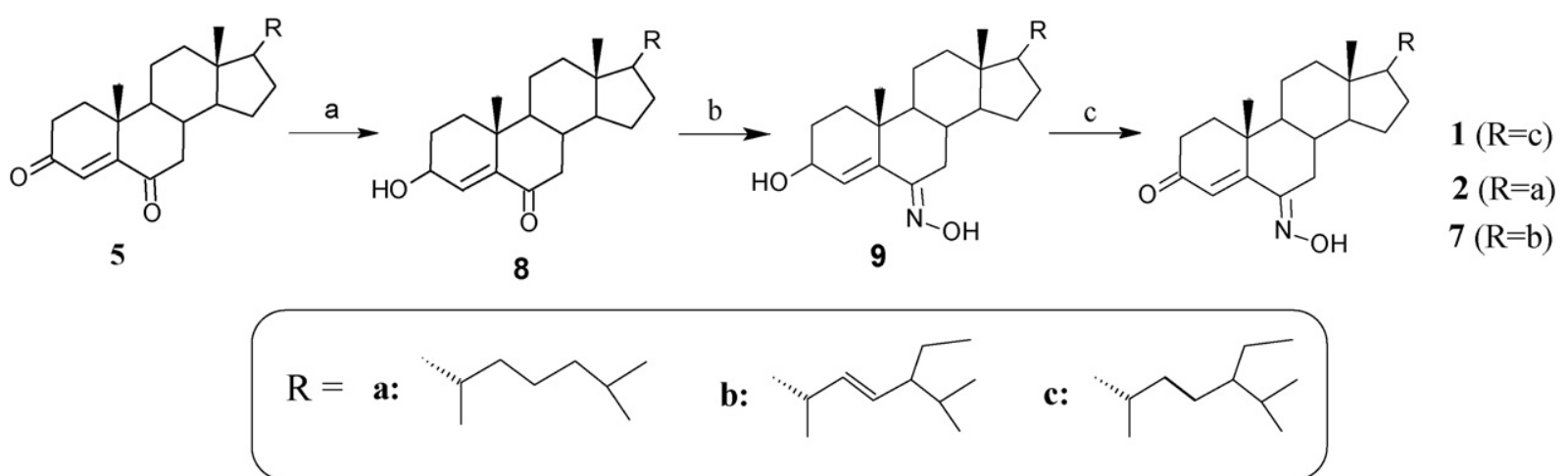

Scheme 2 - Reagents: (a) $\mathrm{NaBH}_{4} / \mathrm{CH}_{3} \mathrm{OH}, \mathrm{CoCl}_{2} \cdot 6 \mathrm{H}_{2} \mathrm{O}$ (8a: 88\%); (b) $\mathrm{NaAc} \cdot 3 \mathrm{H}_{2} \mathrm{O}, 95 \% \mathrm{C}_{2} \mathrm{H}_{5} \mathrm{OH}, \mathrm{H}_{2} \mathrm{OH} \cdot \mathrm{HCl}$ (9a: $75 \%$ ); (c) Jones' reagent, acetone (2: $61 \%)$.

generated analogue 14a and 15a. The downfield chemical shift of $\mathrm{H}-6$ at $6.568 \mathrm{ppm}$ (5.706 ppm for 13a) for $15 \mathrm{a}$ confirmed the $\mathrm{Z}$ configuration of the oxime group because of the influence of hydroxy in the hydroxyimino group.

Synthesis of analogues of (3E)-hydroximino-4-ene steroids (Scheme 4)

The compounds $18 \mathrm{a}-\mathrm{c}$ lacking of a substituted group on B ring were synthesized from the compound 4 a which was oxidized to 5-ene-3-one (16a) with Jones' reagent in acetone and subsequent treatment with oxalic acid gave 4-ene-3-one (17a) in $83 \%$ yield. Oximination of 17 a with hydroxylamine hydrochloride produced the hydroximinosteroid analogues (18a) in $73 \%$ yield.

\section{Synthesis of analogues of}

(3E,6E)-dihydroximino-4-ene steroids (Scheme 5)

We synthesized steroid analogues with two hydroxyimino groups on the steroidal rings. Two hydroxyimino groups were introduced by oximination of $5 a$ and $b$ in the presence of superfluous hydroxylamine hydrochloride to generate the compound 19a and $\mathrm{b}$.

\section{E-Hydroximinocholest-4-en-6-ol}

The compound 20 as shown in Scheme 6 was produced by the reduction of the compound 3 . In the presence of $\mathrm{CeCl}_{3} \cdot 7 \mathrm{H}_{2} \mathrm{O}$ as an additive in the reaction, the compound 20 with $6 \beta-\mathrm{OH}$ was obtained as a major product.

\section{Biological evaluation}

To evaluate the effect of the location of the hydroximino group(s) and the type of a side chain at position 17 on the biological functions of steroidal analogues, we determined the cytotoxicity of these compounds to a variety of cancer cell types such as Sk-Hep-1 (human liver carcinoma cell line), $\mathrm{H}$ 292 (human lung carcinoma cell line), PC-3 (human prostate carcinoma cell line) and Hey-1B (human ovarian carcinoma cell line) cells. Interestingly, we found that the biological activity of a steroidal oxime was significantly dependent on the location of the hydroximino group(s) and the type of a side chain at position 17 on the parental steroid. The results, expressed as IC $_{50}$ values in $\mu$ g, are summarized in Table 1.

Apparently the structure of a side chain at position 17 on the steroidal oxime plays an important role in its cytotoxicity against cancer cells. An increased antineoplastic activity among these analogueues was observed along with the order of the side chain attached at position 17: cholesterol-type side chain $(2,15 a, 19 a)>$ stigmasterol-type side chain $(7,15 b$, $19 b)$ >sitosterol-type side chain $(1,19 c)$. The presence of a cholesterol-type side chain appears to be necessary for the biological activity. The analogues $2,7,1$, with an oxime group at C-6, showed a remarkable increase in their cytotoxic activity in comparison with the analogues $3,6 b, 6 c$, which have an oxime group at C-3. The compound $18 \mathrm{a}-\mathrm{c}$ without any substitute group on ring $B$, were found no obvious cytotoxicity against these cancer cells.<smiles>[R]C1CCC2C3CC=C4C[C@@H](O)CCC4(C)C3CCC12C</smiles>

4

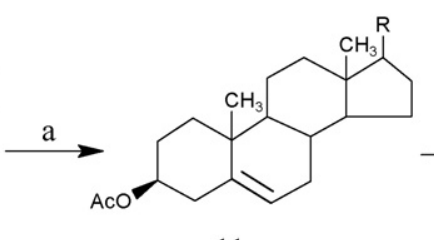

11

b:

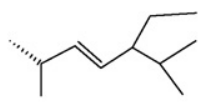<smiles>[R]C1CCC2C3C(=O)C=C4C[C@@H]([R9])CC[C@@]4(C)[C@H]3CCC12C</smiles>

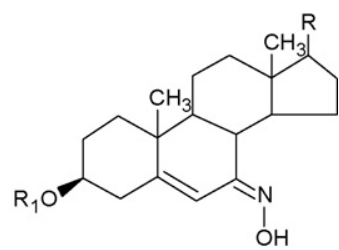

c $\left\{\begin{array}{l}12, R_{1}=A c \\ 13, R_{1}=H\end{array}\right.$

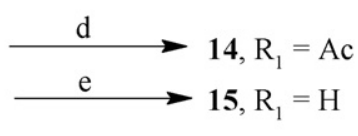

Scheme 3 - Reagents: (a) $\mathrm{Ac}_{2} \mathrm{O} / \mathrm{Py}$ (11a: 97\%); (b) $\mathrm{CrO}_{3} / \mathrm{Py}, \mathrm{CH}_{2} \mathrm{Cl}_{2}$ (12a: 71\%); (c) $\mathrm{K}_{2} \mathrm{CO}_{3}, \mathrm{CH}_{3} \mathrm{OH}$, reflux (13a: 73\%); (d) $\mathrm{NH}_{2} \mathrm{OH} \cdot \mathrm{HCl}, \mathrm{AcONa}$, EtOH (14a: 95\%); (e) $\mathrm{NH}_{2} \mathrm{OH} \cdot \mathrm{HCl}, \mathrm{NaOH}, \mathrm{EtOH}$ (15a: 99\%). 

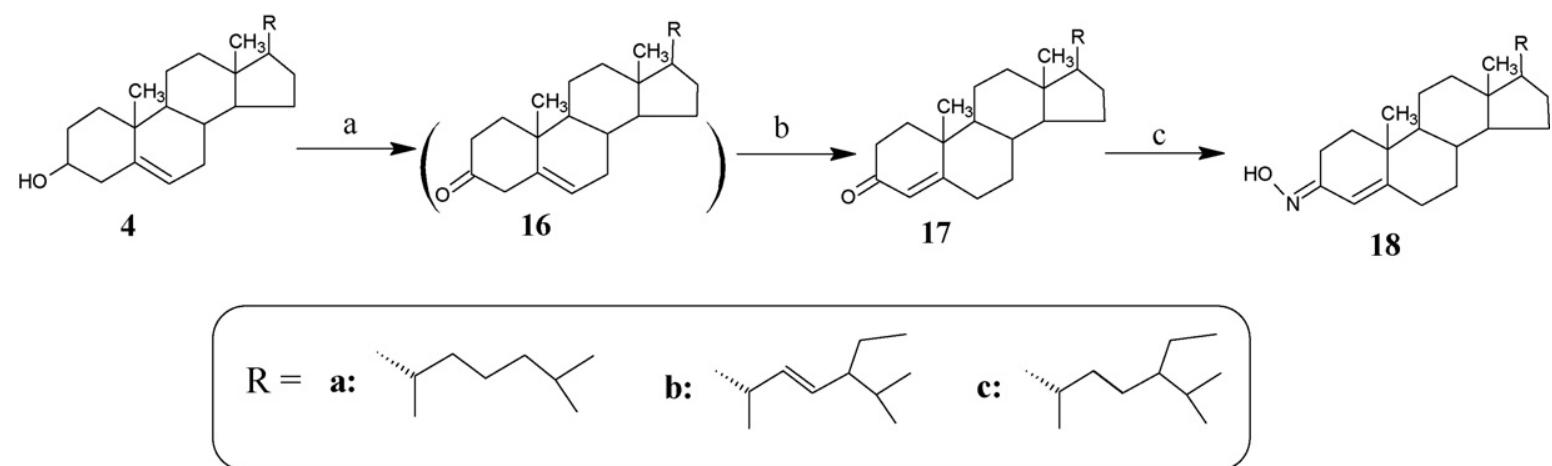

Scheme 4 - Reagents: (a) Jones' reagent, acetone (16a: 83\%); (b) oxalic acid, EtOH (17a: 89\%); (c) $\mathrm{NH}_{2} \mathrm{OH} \cdot \mathrm{HCl}, \mathrm{AcONa}, \mathrm{EtOH}$ (18a: $73 \%)$.<smiles>[R]C1CCC2C3CC(=O)C4=CC(=O)CCC4(C)C3CCC12C</smiles>

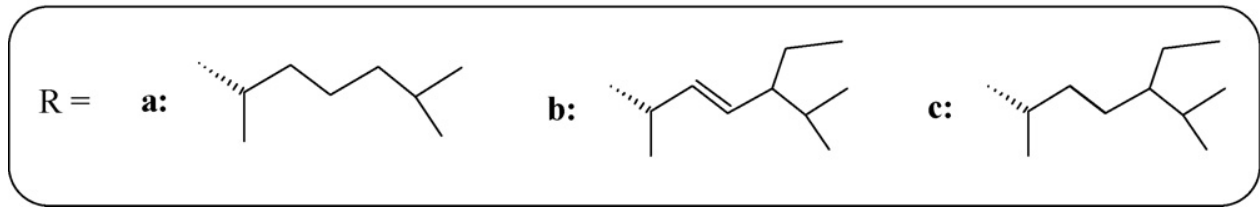

Scheme 5 - Reagents: (a) $\mathrm{NH}_{2} \mathrm{OH} \cdot \mathrm{HCl}, \mathrm{AcONa}, \mathrm{EtOH}(19 \mathrm{a}: 96 \%)$.

The conversion of a hydroxyl group to a keto group at C3 resulted in a dramatic loss of cytotoxic activity, suggesting the importance of the hydroxyl group in the biological function of a steroidal oxime (comparing the $\mathrm{IC}_{50}$ values of $9 \mathrm{a} / 2,9 \mathrm{~b} / 7,9 \mathrm{c} / 1$ and 20/3 in Table 1). This result is different from the conclusion obtained by Rodriguez and co-workers [6]. The reason for that is under investigation.

Compounds 2 and 7, with a hydroximino group at C-6, showed a slight increase in their cytotoxic activity when compared to compound $15 \mathrm{a}$ and $15 \mathrm{~b}$ with the same group at C-7 (except of Sk-Hep-1 and Hey-1B cell lines for 2/15a). However, after the 3-hydroxy on $15 a$ or $15 b$ was acetylated, the cytotoxic activity of the compounds was markedly decreased (the $\mathrm{IC}_{50}$ values of $15 a / 14 a, 15 b / 14 b$ in Table 1 ).

Compound 19a, with a cholesterol-type side chain and two oxime groups at C-3 and C-6, showed a slight increase in its cytotoxicity against Sk-Hep-1 and Hey-1B cells in comparison of compound 2 with the same side chain at position 17 , a keto at C-3 and a oxime group at C-6. However, 19b with a stigmasterol-type side chain and a similar steroidal nucleus was less active than analogues 7 of compound 2. Furthermore, conversion of the oxime group at C-6 $(19 a, 19 b)$ to a keto (3, $6 \mathrm{~b})$ caused a loss of activity indicating that an oxime on ring B (analogues 2, 7, 15a, 15b, 19a and 19b) or a hydroxy group<smiles>CC(C)CCC[C@H](C)C1CCC2C3CC(=O)C4=CC(=NO)CCC4(C)C3CCC21C</smiles><smiles>CC(C)CCC[C@H](C)C1CCC2C3C[C@H](O)C4=C/C(=N/O)CCC4(C)C3CCC21C</smiles> 
066

Table 1 - In vito antitumor activities $\left(\mathrm{IC}_{50}\right.$ in $\mu \mathrm{g} / \mathrm{mL}$ ) of the synthetic hydroximinosteroid analogues.

Compound

1

2

3

$6 \mathrm{~b}$

$6 c$

7

qa

$9 b$

qc

$14 a$
Structure $^{a}$

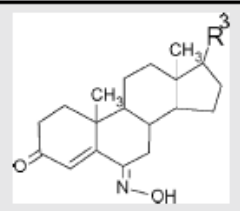

$>100$

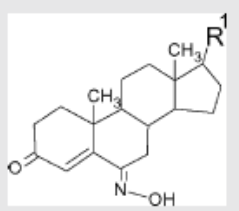

33
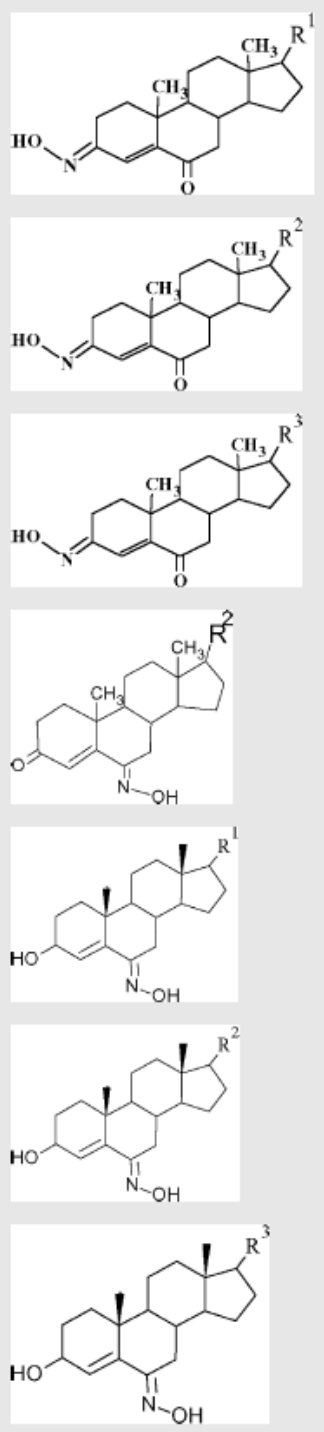

45

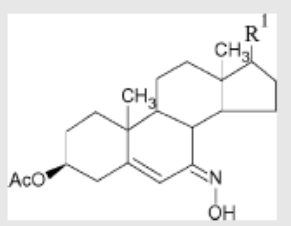

$>100$

37

$>100$
$>100$

$>100$

$>100$

$>100$

$>100$

20.1

26.2

37

$>100$
35

$>100$

$>100$

$>100$

59.5

32.5

40.5

45

41.5

53

54

$>100$

$>100$

49

26.3

62.5

$>100$ 


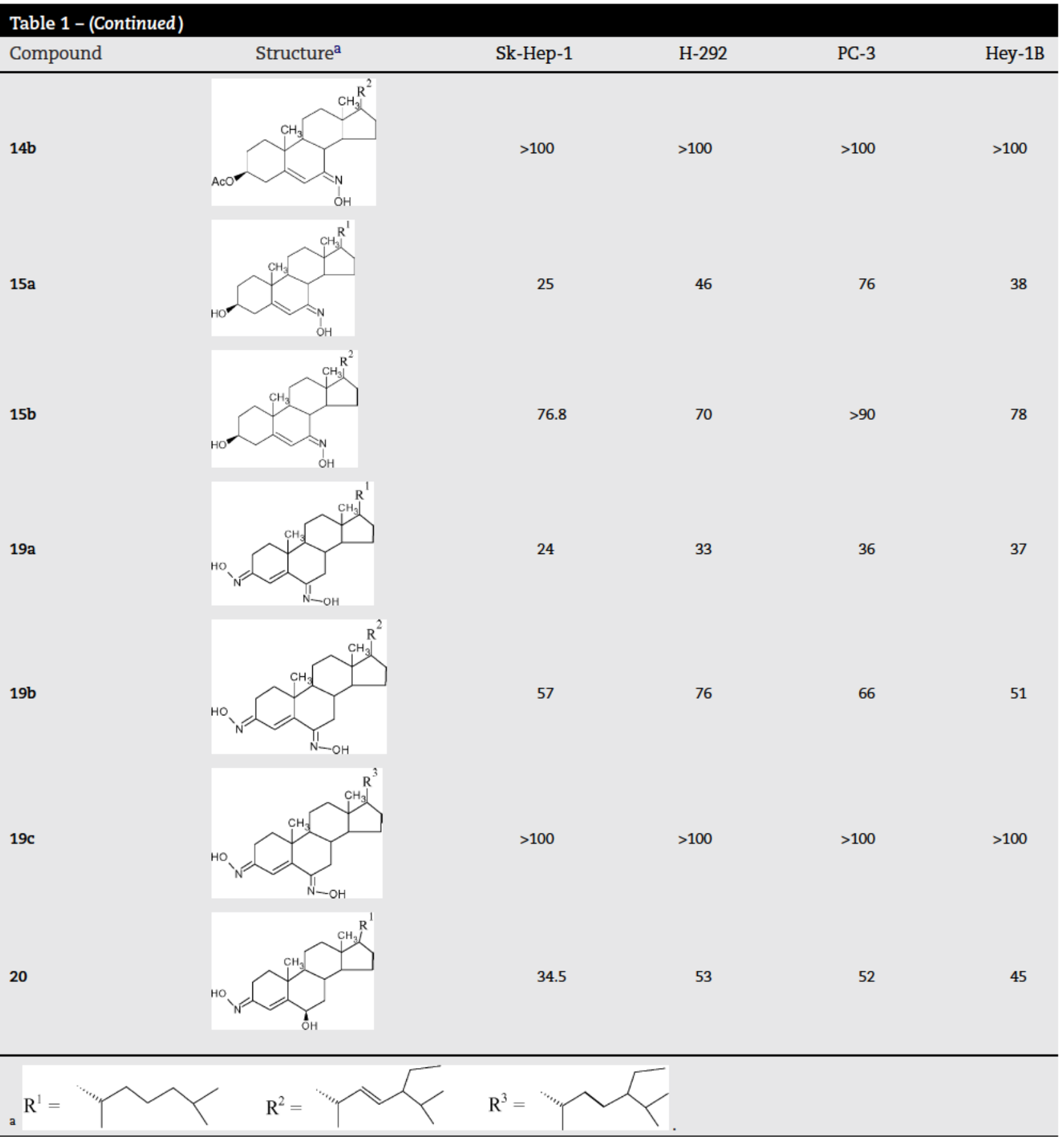

on ring B (20) plays a key role in enhancing the cytotoxicity of this type of compounds.

\section{Conclusions}

We have prepared a series of hydroximinosteroid derivatives with different substituted groups and the position of a hydroximino on the ring $\mathrm{A}$ and $\mathrm{B}$, and different side chains. The cytotoxicity of the synthesized compounds against sk-Hep-1 (human liver carcinoma cell line), H-292 (human lung carcinoma cell line), PC-3 (human prostate carcinoma cell line) and Hey-1B (human ovarian carcinoma cell line) cells was investigated. The results have demonstrated that the presence of a cholesterol-type side chain is very important in determining the biological activity of these compounds. We have found that presence of a hydroximino on the $B$ ring and a hydroxy on the A ring or B ring resulted in an increase of cytotoxic activity for the compounds against tumor cells. Our findings provide new evidence showing the relationship between the chemical structure and biological function. The information obtained from the studies may be useful for the design of novel chemotherapeutic drugs for cancer. 


\section{Experimental}

\section{Chemistry}

The sterol and $\mathrm{NaBH}_{4}$ were purchased from the Merck Co. All chemicals and solvents were analytical grade and solvents were purified by general methods before being used. Melting points were determined on an $\mathrm{X}_{4}$ apparatus and were uncorrected. Infrared spectra were measured with a Nicolet FT-360 Spectrophotometer. The ${ }^{1} \mathrm{H}$ and ${ }^{13} \mathrm{C}$ NMR spectra were recorded in $\mathrm{CDCl}_{3}$ on a Bruker AV-500 spectrometer at working frequencies 500 and $125 \mathrm{MHz}$, respectively. Chemical shifts are expressed in ppm $(\delta)$ values and coupling constants $(J)$ in $\mathrm{Hz}$. The cell proliferation assay was performed by a MTS method using 96-well plates in Beckman coulter LD400 AD/LD analysis spectrometer.

Compounds 1, 2 and 7 were prepared according to Ref. [10].

\section{4-Ethylcholest-4-en-3,6-dione (5a)}

Pyridinium chlorochromate (PCC) $(2.564 \mathrm{~g}, 2.0 \mathrm{mmol})$ was added to a solution of sitosterol (4c) $(0.852 \mathrm{~g}, 0.50 \mathrm{mmol})$ in dried $\mathrm{CH}_{2} \mathrm{Cl}_{2}(40 \mathrm{~mL})$ in one portion at room temperature. The reaction was completed in $26 \mathrm{~h}$. To the mixture was then added $30 \mathrm{~mL}$ of $\mathrm{CH}_{2} \mathrm{Cl}_{2}$, and the suspension was poured over a silica gel column and eluted with $\mathrm{CH}_{2} \mathrm{Cl}_{2}$. The resulting solution was washed with cold water and saturated brines. After drying over anhydrous sodium sulfate, the solvent was removed under reduced pressure, and the resulting crude product was purified by chromatography on silica gel using petroleum ether $\left(60-90^{\circ} \mathrm{C}\right) /$ EtOAc $(5: 1)$ as eluent to give $0.75 \mathrm{~g}$ (86\%) of $5 \mathrm{a}$ as pale yellow crystals, $\theta_{\mathrm{mp}} 172-174^{\circ} \mathrm{C}$. IR $(\mathrm{KBr}) v$ : 2959, 1683, 1601, 1581, 1461, 1377, 1246, 1124, 948, $871 \mathrm{~cm}^{-1}$; ${ }^{1} \mathrm{H} \mathrm{NMR}\left(\mathrm{CDCl}_{3}\right): 0.724\left(\mathrm{~s}, 3 \mathrm{H}, 18-\mathrm{CH}_{3}\right), 0.816(\mathrm{~d}, 3 \mathrm{H}, \mathrm{J}=7.0,26-$ or $\left.27-\mathrm{CH}_{3}\right), 0.841\left(\mathrm{~d}, 3 \mathrm{H}, J=7.0,26-\right.$ or $\left.27-\mathrm{CH}_{3}\right), 0.848(\mathrm{t}, 3 \mathrm{H}$, $\left.J=8.0,29-\mathrm{CH}_{3}\right), 0.935\left(\mathrm{~d}, 3 \mathrm{H}, J=6.5,21-\mathrm{CH}_{3}\right), 1.167\left(\mathrm{~s}, 3 \mathrm{H}, 19-\mathrm{CH}_{3}\right)$, 2.13-2.17(m, $1 \mathrm{H}, 2-\mathrm{C} \alpha \mathrm{H}), 2.44-2.58\left(\mathrm{~m}, 2 \mathrm{H}, 7-\mathrm{C}_{\beta} \mathrm{H}\right.$ and $\left.2-\mathrm{C}_{\beta} \mathrm{H}\right)$, 2.682(dd, $1 \mathrm{H}, J=4.5,15.5,7-\mathrm{C} \alpha \mathrm{H}), 6.170(\mathrm{~s}, 1 \mathrm{H}, 4-\mathrm{CH})$.

\section{Cholest-4-en-3,6-dione (5b)}

PCC (2.564 g, $2.4 \mathrm{mmol})$ was added to a solution of cholesterol $(0.924 \mathrm{~g}, 2.2 \mathrm{mmol})$ in dried $\mathrm{CH}_{2} \mathrm{Cl}_{2}(40 \mathrm{~mL})$ in one portion at room temperature. The reaction was completed in $28 \mathrm{~h}$. The workup similar to $5 \mathrm{a}$ provided $0.795 \mathrm{~g}(83.5 \%)$ of $5 \mathrm{~b}$ as pale yellow crystals, $\theta_{\mathrm{mp}} 90-91^{\circ} \mathrm{C}$; IR(KBr) v: 2953, 2865, 1693, 1600, 1486, 1249, 1221, 1117, $942 \mathrm{~cm}^{-1} .{ }^{1} \mathrm{H} \mathrm{NMR}\left(\mathrm{CDCl}_{3}\right): 0.746(\mathrm{~s}, 3 \mathrm{H}$, $\left.18-\mathrm{CH}_{3}\right), 0.886\left(\mathrm{~d}, 3 \mathrm{H}, \mathrm{J}=6.4,26\right.$ or $\left.27-\mathrm{CH}_{3}\right), 0.899(\mathrm{~d}, 3 \mathrm{H}, \mathrm{J}=6.4$, 26 or $\left.27-\mathrm{CH}_{3}\right), 0.952\left(\mathrm{~d}, 3 \mathrm{H}, \mathrm{J}=6.5,21-\mathrm{CH}_{3}\right), 1.172\left(\mathrm{~s}, 3 \mathrm{H}, 19-\mathrm{CH}_{3}\right)$, 2.546(dd, $\left.1 \mathrm{H}, J=5.2,14.6,2-\mathrm{C}_{\beta} \mathrm{H}\right), 2.706(\mathrm{dd}, 1 \mathrm{H}, J=4.0,16.0$, $7-$ $\mathrm{C} \alpha \mathrm{H})$, 6.196(s, 1H, 4-CH).

\section{Stigmast-4,22-dien-3,6-dione (5c)}

$5 \mathrm{c}$ was prepared similarly according to the procedure of $5 \mathrm{a}$. PCC $(1.30 \mathrm{~g}, 6.0 \mathrm{mmol})$ was added to a solution of stigmasterol $(0.50 \mathrm{~g}, 1.2 \mathrm{mmol})$ in dried $\mathrm{CH}_{2} \mathrm{Cl}_{2}(10 \mathrm{~mL})$ in one portion at room temperature. The reaction was completed in $27 \mathrm{~h}$. The workup similar to $5 \mathrm{a}$ gives $0.42 \mathrm{~g}(83 \%)$ of $5 \mathrm{c}$ as pale yellow crystals, $\theta_{\mathrm{mp}} 134-135^{\circ} \mathrm{C}$; $\mathrm{IR}(\mathrm{KBr}) v$ : 2959, 1714, 1686, 1609, $969,864 \mathrm{~cm}^{-1} ;{ }^{1} \mathrm{H} \mathrm{NMR}\left(\mathrm{CDCl}_{3}\right): 0.743\left(\mathrm{~s}, 3 \mathrm{H}, 18-\mathrm{CH}_{3}\right), 0.805(\mathrm{t}, 3 \mathrm{H}$, $\left.J=7.0,29-\mathrm{CH}_{3}\right), 0.798\left(\mathrm{~d}, 3 \mathrm{H}, \mathrm{J}=6.5,26-\right.$ or $\left.27-\mathrm{CH}_{3}\right), 0.849(\mathrm{~d}, 3 \mathrm{H}$,
$J=6.5,26-$ or $\left.27-\mathrm{CH}_{3}\right), 1.036\left(\mathrm{~d}, 3 \mathrm{H}, \mathrm{J}=7.0,21-\mathrm{CH}_{3}\right), 1.169(\mathrm{~s}, 3 \mathrm{H}$, $19-\mathrm{CH}_{3}$ ), 5.040(dd, $1 \mathrm{H}, J=9.0,15.2,22-\mathrm{CH}$ ), 5.150(dd, $1 \mathrm{H}, J=8.5$, $15.2,23-\mathrm{CH}), 6.171(\mathrm{~s}, 1 \mathrm{H}, 4-\mathrm{CH})$.

\section{(3E)-Hydroximinocholest-4-en-6-one (3)}

5a (84 mg, $0.20 \mathrm{mmol}$ ) was dissolved in $10 \mathrm{~mL} \mathrm{95 \%} \mathrm{CH}_{3} \mathrm{CH}_{2} \mathrm{OH}$. After the mixture was heated to $60^{\circ} \mathrm{C} \mathrm{CH}_{3} \mathrm{COONa} \cdot 3 \mathrm{H}_{2} \mathrm{O}(33 \mathrm{mg}$, $0.24 \mathrm{mmol})$ and $\mathrm{NH}_{2} \mathrm{OH} \cdot \mathrm{HCl}(22.0 \mathrm{mg}, 0.32 \mathrm{mmol})$ were added to the solution. The mixture was stirred for $1 \mathrm{~h}$ at $60^{\circ} \mathrm{C}$. Then the reaction was terminated and the majority of solvent was evaporated under reduced pressure. Proper water was added into the reaction mixture, and the product was extracted with ethyl acetate $(3 \times 20 \mathrm{~mL})$. The combined extracts were washed with saturated brine, dried with anhydrous sodium sulfate, and evaporated under reduced pressure. The residue was subjected to chromatography to give $76 \mathrm{mg}$ of $3(87.4 \%)$ as pale yellow crystals, $\theta_{\mathrm{mp}} 136-138^{\circ} \mathrm{C}$; $\mathrm{IR}(\mathrm{KBr}) v\left(\mathrm{~cm}^{-1}\right): 3264$, 2941, 2868, 1683, 1658, 1585, 1462, 1384, 1245, 1176, 1025, 984; ${ }^{1} \mathrm{H} \mathrm{NMR}\left(\mathrm{CDCl}_{3}\right) \delta: 0.735\left(\mathrm{~s}, 3 \mathrm{H}, 18-\mathrm{CH}_{3}\right), 0.889(\mathrm{~d}, 3 \mathrm{H}, \mathrm{J}=6.5 \mathrm{~Hz}$, 26 or $\left.27-\mathrm{CH}_{3}\right), 0.892\left(\mathrm{~d}, 3 \mathrm{H}, \mathrm{J}=6.5,26\right.$ or $\left.27-\mathrm{CH}_{3}\right), 0.948(\mathrm{~d}, 3 \mathrm{H}$, $\left.J=6.5,21-\mathrm{CH}_{3}\right), 1.064\left(\mathrm{~s}, 3 \mathrm{H}, 19-\mathrm{CH}_{3}\right), 2.039-1.976(\mathrm{~m}, 1 \mathrm{H}, 7-\mathrm{C} \alpha \mathrm{H})$, 2.272(ddd, $1 \mathrm{H}, J=18.0,13.5,5.4,2-\mathrm{C}_{\beta} \mathrm{H}$ ), 2.661(dd, $1 \mathrm{H}, J=16.4$, 3.7, 7- $\left.\mathrm{C}_{\beta} \mathrm{H}\right), 3.095(\mathrm{dd}, 1 \mathrm{H}, \mathrm{J}=18.0,3.8,2-\mathrm{C} \alpha \mathrm{H}), 6.776(\mathrm{~s}, 1 \mathrm{H}, 4-\mathrm{CH})$, 8.667(brs, $1 \mathrm{H}, \mathrm{N}-\mathrm{OH}) ;{ }^{13} \mathrm{C} \mathrm{NMR}\left(\mathrm{CDCl}_{3}\right) \delta: 200.9(6-\mathrm{C}), 155.8(3-\mathrm{C})$, 149.2(5-C), 126.3(4-C), 56.7(14-C), 56.05(17-C), 50.0(9-C), 46.0(7C), 42.5(13-C), 39.5(24-C), 39.4(12-C), 38.9(10-C), 36.1(22-C), $35.7(20-C), 33.5(1-C), 33.4(8-C), 28.1(16-C), 28.0(25-C), 24.0(23-$ C), 23.8(15-C), 22.8(26-C), 22.5(27-C), 21.3(11-C), 18.9(19-C), 18.7(2-C), 18.6(21-C), 11.9(18-C).

In the reaction, the compound 2 was obtained as a byproduct in $3.4 \%$ yield.

\section{6-one (6b)}

(3E)-Hydroximino-24-ethylcholest-4,22-dien-

The preparing method is similar to 3, yield $70.6 \%$; $\theta_{\mathrm{mp}}$ $215-216^{\circ} \mathrm{C}$; $\mathrm{IR}(\mathrm{KBr}) v\left(\mathrm{~cm}^{-1}\right)$ : 3289, 3040, 2954, 2864, 1675, 1581, $1454,1238,972 ;{ }^{1} \mathrm{H} \mathrm{NMR}\left(\mathrm{CDCl}_{3}\right) \delta: 0.759\left(\mathrm{~s}, 3 \mathrm{H}, 18-\mathrm{CH}_{3}\right), 0.824(\mathrm{~d}$, $3 \mathrm{H}, J=7.1,26-\mathrm{CH}_{3}$ or $\left.27-\mathrm{CH}_{3}\right), 0.840\left(\mathrm{~d}, 3 \mathrm{H}, J=7.7,26-\mathrm{CH}_{3}\right.$ or $\left.27-\mathrm{CH}_{3}\right), 0.833\left(\mathrm{t}, 3 \mathrm{H}, J=7.5,29-\mathrm{CH}_{3}\right), 0.874(\mathrm{~d}, 3 \mathrm{H}, J=6.3,21-$ $\mathrm{CH}_{3}$ ), 1.069 (s, 3H, 19- $\mathrm{CH}_{3}$ ), 2.271(ddd, $1 \mathrm{H}, \mathrm{J}=18.5,14.0,5.5$, $\left.2-\mathrm{C}_{\beta} \mathrm{H}\right), 2.657\left(\mathrm{dd}, 1 \mathrm{H}, J=16.5,3.5,7-\mathrm{C}_{\beta} \mathrm{H}\right), 3.097(\mathrm{dd}, 1 \mathrm{H}, \mathrm{J}=18.3$, 3.5, 2- $\mathrm{C} \alpha \mathrm{H}), 5.063(\mathrm{dd}, 1 \mathrm{H}, J=15.1,8.6,22-\mathrm{CH}), 5.179(\mathrm{dd}, 1 \mathrm{H}$, $J=15.2,8.6,23-\mathrm{CH}), 6.775(\mathrm{~s}, 1 \mathrm{H}, 4-\mathrm{CH}), 8.386$ (brs, $\mathrm{N}-\mathrm{OH}) .{ }^{13} \mathrm{C}$ $\mathrm{NMR}\left(\mathrm{CDCl}_{3}\right) \quad \delta: 200.9(6-\mathrm{C}), 155.8(3-\mathrm{C}), 149.2(5-\mathrm{C}), 137.9(22-\mathrm{C})$, 129.7(23-C), 126.3(4-C), 56.8(14-C), 55.9(17-C), 51.3(9-C), 50.1(24C), 46.0(13-C), 42.4(10-C), 40.4(20-C), 39.3(7-C), 38.9(12-C), 33.6(8-C), 33.4(25-C), 31.9(1-C), 28.7(16-C), 25.4(2-C), 24.1(28-C), 21.3(15-C), 21.2(11-C), 21.1(21-C), 19.0(26-C), 19.0(27-C), 18.7(19C), $12.2(18-C), 12.1(29-C)$.

(3E)-Hydroximino-24-ethylcholest-4-en-6-one (6c) The preparing method is similar to 3 , yield $79.6 \% \theta_{\mathrm{mp}}$ 190-192 ${ }^{\circ} \mathrm{C}$; IR(KBr) $v\left(\mathrm{~cm}^{-1}\right): 3252,3035,2933,2868,1658$, 1585, 1462, 1376, 1249, 984; ${ }^{1} \mathrm{H} \operatorname{NMR}\left(\mathrm{CDCl}_{3}\right) \delta: 0.741(\mathrm{~s}, 3 \mathrm{H}$, $\left.18-\mathrm{CH}_{3}\right), \quad 0.843\left(\mathrm{~d}, 3 \mathrm{H}, \mathrm{J}=6.8,26-\mathrm{CH}_{3}\right.$ or $\left.27-\mathrm{CH}_{3}\right), 0.865(\mathrm{~d}$, $3 \mathrm{H}, J=6.8,26-\mathrm{CH}_{3}$ or $\left.27-\mathrm{CH}_{3}\right), 0.874\left(\mathrm{t}, 3 \mathrm{H}, J=7.8,29-\mathrm{CH}_{3}\right)$, 0.959(d, 3H, J =6.4, 21- $\mathrm{CH}_{3}$ ), 1.067(s, 3H, 19- $\mathrm{CH}_{3}$ ), 2.271(ddd, $\left.1 \mathrm{H}, J=19.5,14,5.5,2-\mathrm{C}_{\beta} \mathrm{H}\right), 2.663(\mathrm{dd}, 1 \mathrm{H}, J=16.0,3.5,7-$ $\left.\mathrm{C}_{\beta} \mathrm{H}\right), 3.097(\mathrm{dd}, 1 \mathrm{H}, \mathrm{J}=18.3,4.0,2-\mathrm{C} \alpha \mathrm{H}), 6.777(\mathrm{~s}, 1 \mathrm{H}, 4-\mathrm{CH})$, 8.507(brs, N-OH). ${ }^{13} \mathrm{C} \mathrm{NMR}\left(\mathrm{CDCl}_{3}\right) \quad \delta: 200.9(6-\mathrm{C}), 155.9(3-\mathrm{C})$, 
149.2(5-C), 126.3(4-C), 56.7(14-C), 56.0(17-C), 50.1(9-C), 46.0(24C), 45.9(13-C), 42.5(10-C), 39.4(7-C), 38.9(12-C), 36.1(20-C), 33.9(8-C), 33.6(22-C), 33.4(1-C), 29.2(25-C), 28.1(16-C), 26.2(2-C), 24.0(23-C), 23.1(15-C), 21.3(28-C), 19.8(11-C), 19.1(19-C), 19.0(21C), $18.7(26-C), 18.7(27-C), 12.0(18-C), 11.9(29-C)$.

3-Hydroxycholest-5-en-7-one acetate (12a)

$4.400 \mathrm{~g} \mathrm{CrO}_{3}$ was dissolved in a mixture of $8.8 \mathrm{~mL}$ pyridine and $60 \mathrm{~mL} \mathrm{CH}_{2} \mathrm{Cl}_{2}$. After stirring for $10 \mathrm{~min}$, a sulution of 13 (0.640 g) in $20 \mathrm{~mL} \mathrm{CH} \mathrm{Cl}_{2}$ was added slowly. The mixture was stirred at room temperature for $25 \mathrm{~h}$. The reaction mixture was filtered and filtrate was neutralized with $5 \% \mathrm{HCl}$, washed $(\mathrm{NaCl}$, $\mathrm{NaHCO}_{3}$, and water), dried with anhydrous sodium sulfate, and evaporated under reduced pressure. The residue was subjected to chromatography (petroleum ether $\left(60-90^{\circ} \mathrm{C}\right) /$ ether $4: 1)$ to give $480 \mathrm{mg}$ of $12 \mathrm{a}(70.9 \%)$ as a white solid, $\theta_{\mathrm{mp}}$ $156-158^{\circ} \mathrm{C} . \mathrm{IR}(\mathrm{KBr}) \vee\left(\mathrm{cm}^{-1}\right): 2969,1731,1668,1467,1374$, $1190,965,624 ;{ }^{1} \mathrm{H} \mathrm{NMR}\left(\mathrm{CDCl}_{3}\right) \delta: 0.701\left(\mathrm{~s}, 3 \mathrm{H}, 18-\mathrm{CH}_{3}\right), 0.877(\mathrm{~d}$, $3 \mathrm{H}, \mathrm{J}=2.4,26-\mathrm{CH}_{3}$ or $\left.27-\mathrm{CH}_{3}\right), 0.890\left(\mathrm{~d}, 3 \mathrm{H}, \mathrm{J}=2.4,26-\mathrm{CH}_{3}\right.$ or $\left.27-\mathrm{CH}_{3}\right), 0.941\left(\mathrm{~d}, 3 \mathrm{H}, \mathrm{J}=6.5,21-\mathrm{CH}_{3}\right), 1.231\left(\mathrm{~s}, 3 \mathrm{H}, 19-\mathrm{CH}_{3}\right)$, 2.077(s, 3H, $\left.\mathrm{CH}_{3} \mathrm{CO}\right), 4.769-4.705(\mathrm{~m}, 1 \mathrm{H}, 3-\mathrm{C} \alpha \mathrm{H}), 5.724(\mathrm{~d}, 1 \mathrm{H}$, $J=1.6,6-\mathrm{CH})$.

3-Hydroxy-24-ethylcholest-5,22-dien-7-one acetate $(12 b)$

Yield $72 \%, \theta_{\mathrm{mp}} 170-172^{\circ} \mathrm{C}$; $\mathrm{IR}(\mathrm{KBr}) v\left(\mathrm{~cm}^{-1}\right): 2962,2872,1728$, $1675,1458,1377,1254,1037 ;{ }^{1} \mathrm{H} \mathrm{NMR}\left(\mathrm{CDCl}_{3}\right) \delta: 0.713(\mathrm{~s}, 3 \mathrm{H}$, $\left.18-\mathrm{CH}_{3}\right), 0.819\left(\mathrm{~d}, 3 \mathrm{H}, \mathrm{J}=6.4,26-\mathrm{CH}_{3}\right.$ or $\left.27-\mathrm{CH}_{3}\right), 0.825(\mathrm{t}, 3 \mathrm{H}$, $\left.J=7.0,29-\mathrm{CH}_{3}\right), 0.863\left(\mathrm{~d}, 3 \mathrm{H}, \mathrm{J}=6.4,26-\mathrm{CH}_{3}\right.$ or $\left.27-\mathrm{CH}_{3}\right), 1.044(\mathrm{~d}$, $\left.3 \mathrm{H}, \mathrm{J}=6.5,21-\mathrm{CH}_{3}\right), 1.228\left(\mathrm{~s}, 3 \mathrm{H}, 19-\mathrm{CH}_{3}\right), 2.078\left(\mathrm{~s}, 3 \mathrm{H}, \mathrm{CH}_{3} \mathrm{CO}\right)$, 4.735(m, 1H, 3-CH), 5.035(dd, $1 \mathrm{H}, \mathrm{J}=15.1,8.7,22-\mathrm{CH}), 5.185$ (dd, $1 \mathrm{H}, J=15.1,8.7,23-\mathrm{CH}), 5.714(\mathrm{~s}, 1 \mathrm{H}, 6-\mathrm{CH})$.

\section{3-Hydroxycholest-5-en-7-one (13a)}

$\mathrm{K}_{2} \mathrm{CO}_{3}$ solution (13\%) of $15 \mathrm{~mL}$ was added to a solution of $12 \mathrm{a}$ $(0.500 \mathrm{~g})$ in $\mathrm{CH}_{3} \mathrm{OH}(30 \mathrm{~mL})$ at room temperature. The reaction mixture was heated under reflux for $4 \mathrm{~h}$. Then the reaction was terminated and the majority of solvent was evaporated under reduced pressure. $\mathrm{CH}_{2} \mathrm{Cl}_{2}$ of $60 \mathrm{~mL}$ was added to dissolve a solid and the resulting solution was washed with cold water and saturated brines. After drying over anhydrous sodium sulfate, the solvent was removed under reduced pressure, and the resulting crude product was purified by chromatography on silica gel using petroleum ether $\left(60-90^{\circ} \mathrm{C}\right) /$ EtOAc (2:1) as eluent to give $0.330 \mathrm{~g}(73 \%)$ of $13 \mathrm{a}$ as white solid, $\theta_{\mathrm{mp}} 171-172{ }^{\circ} \mathrm{C}$. $\mathrm{IR}(\mathrm{KBr}) \vee\left(\mathrm{cm}^{-1}\right): 3434,2929,2866,1670,1464,1263,1060$, 949, 799; ${ }^{1} \mathrm{H} \mathrm{NMR}\left(\mathrm{CDCl}_{3}\right) \delta: 0.701\left(\mathrm{~s}, 3 \mathrm{H}, 18-\mathrm{CH}_{3}\right), 0.875(\mathrm{~d}, 3 \mathrm{H}$, $J=2.4,26-\mathrm{CH}_{3}$ or $\left.27-\mathrm{CH}_{3}\right), 0.888\left(\mathrm{~d}, 3 \mathrm{H}, \mathrm{J}=2.4,26-\mathrm{CH}_{3}\right.$ or $\left.27-\mathrm{CH}_{3}\right)$, $0.939\left(\mathrm{~d}, 3 \mathrm{H}, \mathrm{J}=6.6,21-\mathrm{CH}_{3}\right), 1.216\left(\mathrm{~s}, 3 \mathrm{H}, 19-\mathrm{CH}_{3}\right), 3.714-3.669(\mathrm{~m}$, $1 \mathrm{H}, 3-\mathrm{C} \alpha \mathrm{H}), 5.707(\mathrm{~d}, 1 \mathrm{H}, \mathrm{J}=1.1,6-\mathrm{CH})$.

24-Ethylcholest-5,22-dien-3-hydroxy-7-one (13b) Yield 95\%, $\theta_{\mathrm{mp}} 153-155^{\circ} \mathrm{C}$; $\mathrm{IR}(\mathrm{KBr}) v\left(\mathrm{~cm}^{-1}\right): 2962,2872,1728$, $1675,1458,1377,1254,1037 ;{ }^{1} \mathrm{H} \mathrm{NMR}\left(\mathrm{CDCl}_{3}\right) \delta: 0.722(\mathrm{~s}, 3 \mathrm{H}, 18-$ $\left.\mathrm{CH}_{3}\right), 0.819\left(\mathrm{~d}, 3 \mathrm{H}, \mathrm{J}=6.4,26-\mathrm{CH}_{3}\right.$ or $\left.27-\mathrm{CH}_{3}\right), 0.826(\mathrm{t}, 3 \mathrm{H}, \mathrm{J}=7.0$, $\left.29-\mathrm{CH}_{3}\right), 0.871\left(\mathrm{~d}, 3 \mathrm{H}, \mathrm{J}=6.4,26-\mathrm{CH}_{3}\right.$ or $\left.27-\mathrm{CH}_{3}\right), 1.051(\mathrm{~d}, 3 \mathrm{H}$, $\left.J=6.7,21-\mathrm{CH}_{3}\right), 1.224\left(\mathrm{~s}, 3 \mathrm{H}, 19-\mathrm{CH}_{3}\right), 3.731-3.677(\mathrm{~m}, 1 \mathrm{H}, 3-\mathrm{C} \alpha \mathrm{H})$, 5.043(dd, $1 \mathrm{H}, \mathrm{J}=15.0,8.6,22-\mathrm{CH}), 5.191(\mathrm{dd}, 1 \mathrm{H}, \mathrm{J}=15.0,8.6,23-$ $\mathrm{CH})$, 5.714(d, $1 \mathrm{H}, \mathrm{J}=1.5,6-\mathrm{CH})$.
(7Z)-Hydroximinocholest-5-en-3-ol acetate (14a) Compound $12 \mathrm{a}(75 \mathrm{mg})$ was dissolved in $10 \mathrm{~mL} 95 \%$ $\mathrm{CH}_{3} \mathrm{CH}_{2} \mathrm{OH}$. After the mixture was stirred for $5 \mathrm{~min}$, $\mathrm{CH}_{3} \mathrm{COONa} \cdot 3 \mathrm{H}_{2} \mathrm{O}(23 \mathrm{mg})$ and $\mathrm{NH}_{2} \mathrm{OH} \cdot \mathrm{HCl}$ (18 mg) were added to the solution. The mixture was stirred for $3.5 \mathrm{~h}$ at room temperature. After removal of the majority of solvent, proper water was added into the reaction mixture, and the product was extracted with ethyl acetate $(3 \times 15 \mathrm{~mL})$. The combined extracts were washed with saturated brine, dried with anhydrous sodium sulfate, and evaporated under reduced pressure. The residue was subjected to column chromatography (silica gel, ethyl acetate/petroleum ether $\left.\left(60-90^{\circ} \mathrm{C}\right) 1: 6\right)$ to afford $73 \mathrm{mg}$ of $14 \mathrm{a}(95 \%)$ as white solid, $\theta_{\mathrm{mp}} 136-137^{\circ} \mathrm{C}$; IR(KBr) $v\left(\mathrm{~cm}^{-1}\right): 3469,2954,2872,1719,1670$, 1466, 1389, 1262, 1037, 956; ${ }^{1} \mathrm{H} \mathrm{NMR}\left(\mathrm{CDCl}_{3}\right) \delta: 0.717(\mathrm{~s}, 3 \mathrm{H}$, $\left.18-\mathrm{CH}_{3}\right), 0.877\left(\mathrm{~d}, 6 \mathrm{H}, \mathrm{J}=1.6,26-\mathrm{CH}_{3}\right.$ or $\left.27-\mathrm{CH}_{3}\right), 0.890(\mathrm{~d}, 6 \mathrm{H}$, $J=1.6,26-\mathrm{CH}_{3}$ or $\left.27-\mathrm{CH}_{3}\right), 0.951\left(\mathrm{~d}, 3 \mathrm{H}, J=6.5,21-\mathrm{CH}_{3}\right), 1.154(\mathrm{~s}$, $\left.3 \mathrm{H}, 19-\mathrm{CH}_{3}\right), 2.064\left(\mathrm{~s}, 3 \mathrm{H}, \mathrm{CH}_{3} \mathrm{CO}\right), 4.769-4.676(\mathrm{~m}, 1 \mathrm{H}, 3-\mathrm{C} \alpha \mathrm{H})$, $6.591(\mathrm{~s}, 1 \mathrm{H}, 6-\mathrm{CH}), 6.970(\mathrm{~s}, 1 \mathrm{H},=\mathrm{N}-\mathrm{OH}) .{ }^{13} \mathrm{C} \mathrm{NMR}\left(\mathrm{CDCl}_{3}\right)$ $\delta: \quad 170.3(-C=0), \quad 163.8(7-C), \quad 152.0(5-C), 113.8(6-C), 73.0(3-C)$, $54.7(17-C), 50.2(14-C), 49.6(13-C), 42.9(9-C), 39.5(8-C), 38.7(10-$ C), 38.3(24-C), 38.1(12-C), 38.0(4-C), 37.8(1-C), 36.2(22-C), $35.7(20-C), 28.3(16-C), 28.0(25-C), 27.5(2-C), 27.2(15-C), 23.9(23-$ C), 22.8(26-C), 22.6(27-C), 20.8(11-C), 18.9(21-C), 17.9(19-C), $12.2(18-\mathrm{C})$.

(7Z)-Hydroximino-24-ethylcholest-5, 22-dien-3-ol

acetate $(14 b)$

Yield 93\%, $\theta_{\mathrm{mp}} 140-142^{\circ} \mathrm{C}$; $\mathrm{IR}(\mathrm{KBr}) v\left(\mathrm{~cm}^{-1}\right): 3407,2958,2872$, 1732, 1662, 1467, 1368, 1246, 1037, 972; ${ }^{1} \mathrm{H} \operatorname{NMR}\left(\mathrm{CDCl}_{3}\right) \delta$ : $0.737\left(\mathrm{~s}, 3 \mathrm{H}, 18-\mathrm{CH}_{3}\right), 0.820\left(\mathrm{~d}, 3 \mathrm{H}, \mathrm{J}=7.0,26-\mathrm{CH}_{3}\right.$ or $\left.27-\mathrm{CH}_{3}\right)$, $0.827\left(\mathrm{t}, 3 \mathrm{H}, J=5.5,29-\mathrm{CH}_{3}\right), 0.835\left(\mathrm{~d}, 3 \mathrm{H}, J=7.0,26-\mathrm{CH}_{3}\right.$ or $\left.27-\mathrm{CH}_{3}\right), 0.871\left(\mathrm{~d}, 3 \mathrm{H}, \mathrm{J}=5.5,21-\mathrm{CH}_{3}\right), 1.159\left(\mathrm{~s}, 3 \mathrm{H}, 19-\mathrm{CH}_{3}\right)$, 2.067(s, 3H, $\left.\mathrm{CH}_{3} \mathrm{COO}-\right)$, 4.749-4.700(m, 1H, 3-C $\left.\alpha \mathrm{H}\right), 5.043(\mathrm{dd}$, $1 \mathrm{H}, J=15.0,8.5,22-\mathrm{CH}), 5.201$ (dd, $1 \mathrm{H}, J=15.0,9.0,23-\mathrm{CH})$, 6.589(s, $1 \mathrm{H}, 6-\mathrm{CH}), 6.881(\mathrm{~s}, 1 \mathrm{H},=\mathrm{N}-\mathrm{OH}) .{ }^{13} \mathrm{C} \mathrm{NMR}\left(\mathrm{CDCl}_{3}\right) \delta$ : 170.3 $(-\mathrm{C}=\mathrm{O}), 163.8(7-\mathrm{C}), 152.1(5-\mathrm{C}), 138.2(22-\mathrm{C}), 129.5(23-\mathrm{C})$, 113.7(6-C), 73.0(3-C), 54.7(17-C), 51.2(14-C), 50.1(24-C), 49.7(13C), $\quad 43.0(20-C), \quad 42.8(9-C), \quad 40.3(8-C), \quad 40.2(10-C), \quad 38.6(12-C)$, $38.1(4-C), 37.8(1-C), 32.0(25-C), 29.0(16-C), 27.5(2-C), 27.3(28-$ C), 25.4(15-C), 21.5(11-C), 21.3( $\left.\mathrm{CH}_{3}-\mathrm{C}=\mathrm{O}\right), 21.1(21-\mathrm{C}), 20.8(26-\mathrm{C})$, 19.0(27-C), 17.9(19-C), 12.4(29-C), 12.3(18-C).

(7Z)-Hydroximinocholest-5-en-3-ol (15a)

$\mathrm{NaOH}$ solution $(0.25 \mathrm{~mol} / \mathrm{L})$ of $1.3 \mathrm{~mL}$ was added to a solution of $13 \mathrm{a}(83 \mathrm{mg})$ in $95 \% \mathrm{CH}_{3} \mathrm{CH}_{2} \mathrm{OH}(15 \mathrm{~mL})$ at room temperature. After the mixture was stirred for $10 \mathrm{~min}, \mathrm{NH}_{2} \mathrm{OH} \cdot \mathrm{HCl}$ ( $40 \mathrm{mg}$ ) were added to the solution, and the mixture was heated at $78^{\circ} \mathrm{C}$ for $11 \mathrm{~h}$. After removal of the majority of solvent, proper water was added into the reaction mixture, and the product was extracted with ethyl acetate $(3 \times 15 \mathrm{~mL})$. The combined extracts were washed with saturated brine, dried with anhydrous sodium sulfate, and evaporated under reduced pressure. The residue was recrystallized and $84 \mathrm{mg}$ of 15 a (99\%) was obtained as a white crystal, $\theta_{\mathrm{mp}} 235-236^{\circ} \mathrm{C}$; $\operatorname{IR}(\mathrm{KBr}) v\left(\mathrm{~cm}^{-1}\right): 3378,2937,2864,1711,1466,1384,1262,1172$, $1021,959,796 ;{ }^{1} \mathrm{H} \mathrm{NMR}\left(\mathrm{CDCl}_{3}\right) \delta: 0.723\left(\mathrm{~s}, 3 \mathrm{H}, 18-\mathrm{CH}_{3}\right), 0.882(\mathrm{~d}$, $3 \mathrm{H}, J=1.6,26-\mathrm{CH}_{3}$ or $\left.27-\mathrm{CH}_{3}\right), 0.895\left(\mathrm{~d}, 3 \mathrm{H}, J=1.6,26-\mathrm{CH}_{3}\right.$ or $\left.27-\mathrm{CH}_{3}\right), 0.955\left(\mathrm{~d}, 3 \mathrm{H}, \mathrm{J}=6.5,21-\mathrm{CH}_{3}\right), 1.149\left(\mathrm{~s}, 3 \mathrm{H}, 19-\mathrm{CH}_{3}\right)$, 3.708-3.628(m, 1H, 3-C $\alpha \mathrm{H}), 6.568(\mathrm{~s}, 1 \mathrm{H}, 6-\mathrm{CH}), 7.119(\mathrm{~s}, 1 \mathrm{H}, 7$ 
$=\mathrm{N}-\mathrm{OH}) ;{ }^{13} \mathrm{C} \mathrm{NMR}\left(\mathrm{CDCl}_{3}\right) \delta: 158.2(7-\mathrm{C}), 153.5(5-\mathrm{C}), 112.8(6-\mathrm{C})$, 71.2(3-C), 54.8(17-C), 50.3(14-C), 49.8(13-C), 42.9(4-C), 42.2(9-C), 39.5(8-C), 38.6(10-C), 38.4(24-C), 38.0(12-C), 36.7(1-C), 36.2(22C), 35.6(20-C), 31.3(2-C), 28.3(16-C), 28.0(25-C), 27.2(15-C), 23.8(23-C), 22.8(26-C), 22.6(27-C), 20.8(11-C), 19.0(21-C), 18.0(19C), $12.2(18-\mathrm{C})$

\section{(7Z)-Hydroximino-24-ethylcholest-5, 22-dien-3-ol}

\section{(15b)}

Yield 99\%, $\theta_{\mathrm{mp}} 232-233^{\circ} \mathrm{C}$; $\mathrm{IR}(\mathrm{KBr}) v\left(\mathrm{~cm}^{-1}\right): 3378,2937,2864$ 1711, 1466, 1384, 1262, 1172, 1021, 959, 796; ${ }^{1} \mathrm{H} \mathrm{NMR}\left(\mathrm{CDCl}_{3}\right)$ $\delta: 0.739\left(\mathrm{~s}, 3 \mathrm{H}, 18-\mathrm{CH}_{3}\right), 0.821\left(\mathrm{~d}, 3 \mathrm{H}, \mathrm{J}=6.5,26-\mathrm{CH}_{3}\right.$ or $27-$ $\left.\mathrm{CH}_{3}\right), 0.828\left(\mathrm{t}, 3 \mathrm{H}, \mathrm{J}=7.5,29-\mathrm{CH}_{3}\right), 0.870\left(\mathrm{~d}, 3 \mathrm{H}, \mathrm{J}=6.5,26-\mathrm{CH}_{3}\right.$ or $\left.27-\mathrm{CH}_{3}\right), 1.060\left(\mathrm{~d}, 3 \mathrm{H}, J=6.6,21-\mathrm{CH}_{3}\right), 1.149\left(\mathrm{~s}, 3 \mathrm{H}, 19-\mathrm{CH}_{3}\right)$, $3.702-3.635(\mathrm{~m}, 1 \mathrm{H}, 3-\mathrm{C} \alpha \mathrm{H}), 5.046(\mathrm{dd}, 1 \mathrm{H}, \mathrm{J}=15.0,8.5,22-\mathrm{CH})$, 5.200 (dd, $1 \mathrm{H}, \mathrm{J}=15.0,9.0,23-\mathrm{CH}$ ), 6.566(s, 1H, 6-CH), 7.093(s, 1H, $=\mathrm{N}-\mathrm{OH}) ;{ }^{13} \mathrm{C} \mathrm{NMR}\left(\mathrm{CDCl}_{3}\right) \delta: 158.1(7-\mathrm{C}), 153.4(5-\mathrm{C}), 138.2(22-\mathrm{C})$, 129.4(23-C), 112.8(6-C), 71.2(3-C), 54.7(17-C), 51.2(14-C), 50.4(24C), 49.8(13-C), 42.8(20-C), 42.2(4-C), 40.1(9-C), 38.5(10-C), 38.4(12-C), 38.0(1-C), 36.7(8-C), 31.9(25-C), 31.4(2-C), 28.8(16-C), 27.3(28-C), 25.4(15-C), 21.5(11-C), 21.0(21-C), 20.8(26-C), 19.0(27C), $18.0(19-C), 12.4(29-C), 12.2(18-C)$.

\section{Cholest-4-en-3-one (17a)}

The Jones' reagent of $1 \mathrm{~mL}(0.267 \mathrm{~mol} / \mathrm{L})$ was gradually added into the solution of $4 \mathrm{a}(386 \mathrm{mg}, 1 \mathrm{mmol})$ in $50 \mathrm{~mL}$ of acetone in $10 \mathrm{~min}$. The reaction mixture was stirred at $0{ }^{\circ} \mathrm{C}$ for $15 \mathrm{~min}$ and then neutralized with $10 \% \mathrm{~K}_{2} \mathrm{CO}_{3}$ solution. The majority of solvent was evaporated under reduced pressure and then the product was extracted with ethyl acetate $(3 \times 20 \mathrm{~mL})$. The combined extracts were washed with saturated brine, dried with anhydrous sodium sulfate, and evaporated under reduced pressure. The crude product was recrystallized in $\mathrm{CH}_{3} \mathrm{OH}$ to obtain 16 a a a white crystal. The white crystal was dissolved in $5 \mathrm{~mL} 95 \% \mathrm{CH}_{3} \mathrm{CH}_{2} \mathrm{OH}$, and subsequent treatment with oxalic acid gave cholest-4-en-3-one 17 a as pale yellow crystals in $89 \%$ yield. $\theta_{\mathrm{mp}} 84-85^{\circ} \mathrm{C}$; $\mathrm{IR}(\mathrm{KBr}) \vee\left(\mathrm{cm}^{-1}\right): 3019,2945,2864,1670$, $1609,1462,1376,1333,1266,1225,1192,1026,951,922,865 ;{ }^{1} \mathrm{H}$ $\mathrm{NMR}\left(\mathrm{CDCl}_{3}\right) \delta: 0.737\left(\mathrm{~s}, 3 \mathrm{H}, 18-\mathrm{CH}_{3}\right), 0.886\left(\mathrm{~d}, 3 \mathrm{H}, \mathrm{J}=2.5,26-\mathrm{CH}_{3}\right.$ or $\left.27-\mathrm{CH}_{3}\right), 0.899\left(\mathrm{~d}, 3 \mathrm{H}, \mathrm{J}=2.5,26-\mathrm{CH}_{3}\right.$ or $\left.27-\mathrm{CH}_{3}\right), 0.938(\mathrm{~d}, 3 \mathrm{H}$, $\left.J=6.5,21-\mathrm{CH}_{3}\right), 1.207\left(\mathrm{~s}, 3 \mathrm{H}, 19-\mathrm{CH}_{3}\right), 2.428(\mathrm{dd}, 1 \mathrm{H}, J=14.5,5.3$, 2- $\mathrm{C}_{\beta} \mathrm{H}$ ), 2.461(dd, $\left.1 \mathrm{H}, \mathrm{J}=15.0,5.3,2-\mathrm{C} \alpha \mathrm{H}\right), 5.747(\mathrm{~s}, 1 \mathrm{H}, 4-\mathrm{CH})$.

24-Ethylcholest-4,22-dien-3-one (17b)

Yield 85\%, $\theta_{\mathrm{mp}} 121-122^{\circ} \mathrm{C}$; $\operatorname{IR}(\mathrm{KBr}) v\left(\mathrm{~cm}^{-1}\right): 2969,2937$, 2871, 1679, 1619, 1462, 1446, 1435, 1384, 1270, 1229, 994 961, 868; ${ }^{1} \mathrm{H} \operatorname{NMR}\left(\mathrm{CDCl}_{3}\right) \quad \delta: 0.748\left(\mathrm{~s}, 3 \mathrm{H}, 18-\mathrm{CH}_{3}\right), 0.816(\mathrm{~d}$, $3 \mathrm{H}, J=6.5,26-\mathrm{CH}_{3}$ or $\left.27-\mathrm{CH}_{3}\right), 0.824\left(\mathrm{t}, 3 \mathrm{H}, J=7.3,29-\mathrm{CH}_{3}\right)$, $0.866\left(\mathrm{~d}, 3 \mathrm{H}, \mathrm{J}=6.5,26-\mathrm{CH}_{3}\right.$ or $\left.27-\mathrm{CH}_{3}\right), 1.037(\mathrm{~d}, 3 \mathrm{H}, J=6.6,21-$ $\left.\mathrm{CH}_{3}\right), 1.203\left(\mathrm{~s}, 3 \mathrm{H}, 19-\mathrm{CH}_{3}\right), 2.282(\mathrm{ddd}, 1 \mathrm{H}, \mathrm{J}=14.5,4.0,2.5$, 6- $\mathrm{C} \alpha \mathrm{H}), 2.356\left(\mathrm{dt}, 1 \mathrm{H}, J=16.5,4.0,6-\mathrm{C}_{\beta} \mathrm{H}\right), 2.426(\mathrm{dd}, 1 \mathrm{H}, J=14.5$, $\left.5.2,2-\mathrm{C}_{\beta} \mathrm{H}\right), 2.459(\mathrm{dd}, 1 \mathrm{H}, J=15.0,5.2,2-\mathrm{C} \alpha \mathrm{H}), 5.040(\mathrm{dd}, 1 \mathrm{H}$ $J=15.1,8.7,22-\mathrm{CH}), 5.165(\mathrm{dd}, 1 \mathrm{H}, J=15.1,8.7,23-\mathrm{CH}), 5.743$ (s, $1 \mathrm{H}, 4-\mathrm{CH})$.

\section{4-Ethylcholest-4-en-3-one (17c)}

Yield 85\%, $\theta_{\mathrm{mp}} 161-163^{\circ} \mathrm{C}$; IR(KBr) v $\left(\mathrm{cm}^{-1}\right): 2957,2039,2867$, 2852, 1681, 1620, 1466, 1438, 1384, 1367, 1271, 1120, 1030, 867; ${ }^{1} \mathrm{H} \mathrm{NMR}\left(\mathrm{CDCl}_{3}\right) \delta: 0.719\left(\mathrm{~s}, 3 \mathrm{H}, 18-\mathrm{CH}_{3}\right), 0.836(\mathrm{~d}, 3 \mathrm{H}, \mathrm{J}=6.5,26-$ $\mathrm{CH}_{3}$ or $\left.27-\mathrm{CH}_{3}\right), 0.867\left(\mathrm{t}, 3 \mathrm{H}, \mathrm{J}=7.5,29-\mathrm{CH}_{3}\right), 0.859$ (d, $3 \mathrm{H}, \mathrm{J}=6.5$,
$26-\mathrm{CH}_{3}$ or $27-\mathrm{CH}_{3}$ ), 0.930(d, 3H, $J=7.5,21-\mathrm{CH}_{3}$ ), 1.120 (s, 3H, 19$\left.\mathrm{CH}_{3}\right), 6.486(\mathrm{~s}, 1 \mathrm{H}, 4-\mathrm{CH})$.

\section{(3E)-Hydroximinocholest-4-en (18a)}

Compound 17a (60 mg, $0.156 \mathrm{mmol}$ ) was dissolved in $10 \mathrm{~mL}$ $95 \% \mathrm{CH}_{3} \mathrm{CH}_{2} \mathrm{OH}$. After the mixture was heated to $60^{\circ} \mathrm{C}$, $\mathrm{CH}_{3} \mathrm{COONa} \cdot 3 \mathrm{H}_{2} \mathrm{O}(25 \mathrm{mg}, 0.18 \mathrm{mmol})$ and $\mathrm{NH}_{2} \mathrm{OH} \cdot \mathrm{HCl}(15 \mathrm{mg}$, $0.21 \mathrm{mmol}$ ) were added into the solution. The mixture was stirred for $1 \mathrm{~h}$ at $60^{\circ} \mathrm{C}$. Then the reaction was terminated and the majority of solvent was evaporated under reduced pressure. Proper water was added into the reaction mixture, and the product was extracted with ethyl acetate $(3 \times$ $20 \mathrm{~mL}$ ). The combined extracts were washed with saturated brine, dried with anhydrous sodium sulfate, and evaporated under reduced pressure. The residue was subjected to chromatography to produce $46 \mathrm{mg}$ of $18 \mathrm{a}$ (73\%) as pale yellow crystals, $\theta_{\mathrm{mp}} 158-159^{\circ} \mathrm{C}$; $\mathrm{IR}(\mathrm{KBr}) v\left(\mathrm{~cm}^{-1}\right): 3276,3066,2933$, 2864, 1629, 1466, 1376, 1291, 1237, 1200, 1134, 997, 967, 930, $857 ;{ }^{1} \mathrm{H} \mathrm{NMR}\left(\mathrm{CDCl}_{3}\right) \delta: 0.722\left(\mathrm{~s}, 3 \mathrm{H}, 18-\mathrm{CH}_{3}\right), 0.884(\mathrm{~d}, 3 \mathrm{H}, \mathrm{J}=2.0$, $26-\mathrm{CH}_{3}$ or $\left.27-\mathrm{CH}_{3}\right), 0.897\left(\mathrm{~d}, 3 \mathrm{H}, \mathrm{J}=2.0,26-\mathrm{CH}_{3}\right.$ or $\left.27-\mathrm{CH}_{3}\right)$, 0.934(d, 3H, J=6.7, 21- $\left.\mathrm{CH}_{3}\right), 1.084\left(\mathrm{~s}, 3 \mathrm{H}, 19-\mathrm{CH}_{3}\right), 2.137$ (ddd, $1 \mathrm{H}, J=17.0,14.0,5.2,6-\mathrm{C}_{\beta} \mathrm{H}$ ), 2.232(ddd, $1 \mathrm{H}, J=14.0,4.0,2.0$, 6- $\mathrm{C} \alpha \mathrm{H}$ ), 2.324(ddd, $1 \mathrm{H}, J=14.0,5.0,2.0,2-\mathrm{C}_{\beta} \mathrm{H}$ ), 3.061(ddd, $1 \mathrm{H}$, $J=18.5,5.0,2.5,2-\mathrm{C} \alpha \mathrm{H}), 5.777(\mathrm{~s}, 1 \mathrm{H}, 4-\mathrm{CH}) ;{ }^{13} \mathrm{C} \mathrm{NMR}\left(\mathrm{CDCl}_{3}\right) \delta$ : 156.9(3-C), 155.7(5-C), 117.2(4-C), 56.2(14-C), 56.1(17-C), 53.8(9C), 42.4(13-C), 39.9(10-C), 39.6(12-C), 38.0(24-C), 36.2(22-C), 35.9(8-C), 35.8(20-C), 34.7(7-C), 32.5(1-C), 32.2(6-C), 28.2(2-C), 28.0(25-C), 24.3(16-C), 23.9(15-C), 22.9(23-C), 22.6(26-C), 21.4(27C), 18.9(11-C), 18.7(19-C), 17.8(21-C), 12.0(18-C).

In the reaction, the $3 Z$-isomer of $18 \mathrm{a}$ was obtained in $24 \%$ yield, $\theta \mathrm{mp} 97-98^{\circ} \mathrm{C}$; $\operatorname{IR}(\mathrm{KBr}) v\left(\mathrm{~cm}^{-1}\right): 3276,3060$, 2933, 2855, 1634, 1462, 1376, 963, 841; ${ }^{1} \mathrm{H} \operatorname{NMR}\left(\mathrm{CDCl}_{3}\right) \delta$ : $0.722\left(\mathrm{~s}, 3 \mathrm{H}, 18-\mathrm{CH}_{3}\right), 0.883\left(\mathrm{~d}, 3 \mathrm{H}, \mathrm{J}=2.0,26-\mathrm{CH}_{3}\right.$ or $\left.27-\mathrm{CH}_{3}\right)$, $0.896\left(\mathrm{~d}, 3 \mathrm{H}, \mathrm{J}=2.0,26-\mathrm{CH}_{3}\right.$ or $\left.27-\mathrm{CH}_{3}\right), 0.931(\mathrm{~d}, 3 \mathrm{H}, \mathrm{J}=6.5$, $\left.21-\mathrm{CH}_{3}\right), 1.125\left(\mathrm{~s}, 3 \mathrm{H}, 19-\mathrm{CH}_{3}\right), 2.030(\mathrm{dd}, 1 \mathrm{H}, \mathrm{J}=13.0,3.5,6-$ $\left.\mathrm{C}_{\beta} \mathrm{H}\right), 2.288-2.246(\mathrm{~m}, 1 \mathrm{H}, 6-\mathrm{C} \alpha \mathrm{H}), 2.395-2.314(\mathrm{~m}, 1 \mathrm{H}, 2-\mathrm{CH})$, 6.484(s, 1H, 4-CH).

(3E)-Hydroximino-24-ethylcholest-4,22-dien (18b) Yield $70 \%, \theta_{\mathrm{mp}} 168-169^{\circ} \mathrm{C}$; IR(KBr) $v\left(\mathrm{~cm}^{-1}\right): 3285,3046,2951$, 2883, 1629, 1466, 1437, 1372, 1295, 1237, 1218, 1126, 995 , 930, 873; ${ }^{1} \mathrm{H} \mathrm{NMR}\left(\mathrm{CDCl}_{3}\right) \delta: 0.740\left(\mathrm{~s}, 3 \mathrm{H}, 18-\mathrm{CH}_{3}\right), 0.821(\mathrm{~d}, 3 \mathrm{H}$, $J=6.5,26-\mathrm{CH}_{3}$ or $\left.27-\mathrm{CH}_{3}\right), 0.829\left(\mathrm{t}, 3 \mathrm{H}, J=8.0,29-\mathrm{CH}_{3}\right), 0.871(\mathrm{~d}$, $3 \mathrm{H}, J=6.5,26-\mathrm{CH}_{3}$ or $\left.27-\mathrm{CH}_{3}\right), 1.039\left(\mathrm{~d}, 3 \mathrm{H}, J=6.6,21-\mathrm{CH}_{3}\right)$, 1.085(s, 3H, 19- $\mathrm{CH}_{3}$ ), 2.136(ddd, $1 \mathrm{H}, J=17.0,14.0,5.0,6-\mathrm{C}_{\beta} \mathrm{H}$ ), 2.230(ddd, $1 \mathrm{H}, J=14.0,4.0,2.5,6-\mathrm{C} \alpha \mathrm{H}$ ), 2.323(ddd, $1 \mathrm{H}, J=14.0$, $4.5,2.0,2-\mathrm{C}_{\beta} \mathrm{H}$ ), 3.065(ddd, $1 \mathrm{H}, J=17.0,4.5,3.0,2-\mathrm{C} \alpha \mathrm{H}$ ), 5.040 (dd, $1 \mathrm{H} J=15.2,9.0,22-\mathrm{CH}), 5.170(\mathrm{dd}, 1 \mathrm{H}, J=15.2,8.5,23-\mathrm{CH})$, 5.778(s, $1 \mathrm{H}, 4-\mathrm{CH}) ;{ }^{13} \mathrm{C} \mathrm{NMR}\left(\mathrm{CDCl}_{3}\right) \quad \delta: 157.2(3-\mathrm{C}), 155.9(5-$ C), 138.2(22-C), 129.4(23-C), 117.1(4-C), 56.2(14-C), 56.0(17-C), 53.8(9-C), 51.3(24-C), 42.3(13-C), 40.5(10-C), 39.8(20-C), 38.0(12C), 35.9(8-C), 34.7(7-C), 32.6(1-C), 32.3(25-C), 31.9(6-C), 28.9(2-C), 25.4(28-C), 24.3(16-C), 21.4(15-C), 21.2(11-C), 21.1(21-C), 19.0(27C), 18.7(19-C), 17.8(26-C), 12.3(18-C), 12.2(29-C).

The $3 Z$-isomer of $18 \mathrm{~b}$ was obtained in $29 \%$ yield, $\theta_{\mathrm{mp}}$ $166-168^{\circ} \mathrm{C} ; \mathrm{IR}(\mathrm{KBr}) \vee\left(\mathrm{cm}^{-1}\right): 3281,3055,2933,2862,1630$, 1462, 1377, 995, 868; ${ }^{1} \mathrm{HNMR}\left(\mathrm{CDCl}_{3}\right) \delta: 0.737\left(\mathrm{~s}, 3 \mathrm{H}, 18-\mathrm{CH}_{3}\right)$, $0.818\left(\mathrm{~d}, 3 \mathrm{H}, J=6.0,26-\mathrm{CH}_{3}\right.$ or $\left.27-\mathrm{CH}_{3}\right), 0.826(\mathrm{t}, 3 \mathrm{H}, J=7.5$, $\left.29-\mathrm{CH}_{3}\right), 0.868\left(\mathrm{~d}, 3 \mathrm{H}, J=6.0,26-\mathrm{CH}_{3}\right.$ or $\left.27-\mathrm{CH}_{3}\right), 1.034(\mathrm{~d}, 3 \mathrm{H}$, $\left.J=6.6,21-\mathrm{CH}_{3}\right), 1.123\left(\mathrm{~s}, 3 \mathrm{H}, 19-\mathrm{CH}_{3}\right), 2.305-2.335(\mathrm{~m}, 1 \mathrm{H}, 2-\mathrm{C} \alpha \mathrm{H})$, 
4.146(N-OH), 5.036(dd, $1 \mathrm{H}, J=15.1,8.7,22-\mathrm{CH}), 5.165(\mathrm{dd}, 1 \mathrm{H}$, $J=15.1,8.7,23-\mathrm{CH}), 6.482(\mathrm{~s}, 1 \mathrm{H}, 4-\mathrm{CH})$.

(3E)-Hydroximino-24-ethylcholest-4-en (18c)

Yield $70 \%, \theta_{\mathrm{mp}} 174-175^{\circ} \mathrm{C}$; $\mathrm{IR}(\mathrm{KBr}) v\left(\mathrm{~cm}^{-1}\right)$ : 3195, 2958, 2929, 2864, 1660, 1629, 1454, 1397, 1295, 1237, 1200, 1130, 1022, $967,930,868 ;{ }^{1} \mathrm{H} \mathrm{NMR}\left(\mathrm{CDCl}_{3}\right) \delta: 0.720\left(\mathrm{~s}, 3 \mathrm{H}, 18-\mathrm{CH}_{3}\right), 0.836(\mathrm{~d}$, $3 \mathrm{H}, J=6.8,26-\mathrm{CH}_{3}$ or $\left.27-\mathrm{CH}_{3}\right), 0.859\left(\mathrm{~d}, 3 \mathrm{H}, J=6.8,26-\mathrm{CH}_{3}\right.$ or $\left.27-\mathrm{CH}_{3}\right), 0.868\left(\mathrm{t}, 3 \mathrm{H}, J=7.5,29-\mathrm{CH}_{3}\right), 0.938(\mathrm{~d}, 3 \mathrm{H}, J=6.5,21-$ $\left.\mathrm{CH}_{3}\right), 1.081\left(\mathrm{~s}, 3 \mathrm{H}, 19-\mathrm{CH}_{3}\right), 2.136(\mathrm{ddd}, 1 \mathrm{H}, \mathrm{J}=17.0,14.0,5.0$, 6- $\left.\mathrm{C}_{\beta} \mathrm{H}\right), 2.250-2.200(\mathrm{~m}, 1 \mathrm{H}, 6-\mathrm{C} \alpha \mathrm{H}), 2.357-2.289\left(\mathrm{~m}, 1 \mathrm{H}, 2-\mathrm{C}_{\beta} \mathrm{H}\right)$, 3.063(ddd, $1 \mathrm{H}, \mathrm{J}=17.3,4.5,3.0,2-\mathrm{C} \alpha \mathrm{H}), 5.776(\mathrm{~s}, 1 \mathrm{H}, 4-\mathrm{CH})$; ${ }^{13} \mathrm{C} \mathrm{NMR}\left(\mathrm{CDCl}_{3}\right) \delta: 157.3(3-\mathrm{C}), 155.9(5-\mathrm{C}), 117.1(4-\mathrm{C}), 56.1(14-$ C), 56.0(17-C), 53.8(9-C), 45.9(24-C), 42.4(13-C), 39.9(10-C), 38.0(12-C), 36.2(20-C), 35.9(8-C), 34.7(22-C), 34.0(7-C), 32.6(1-C), 32.3(6-C), 29.2(25-C), 28.2(2-C), 26.2(23-C), 24.3(16-C), 23.1(15C), 21.4(28-C), 19.8(11-C), 19.1(27-C), 18.8(19-C), 18.7(26-C), 17.8(21-C), 12.0(29-C), 12.0(18-C).

The 3Z-isomer of $18 \mathrm{c}$ was obtained in $28 \%$ yield, $\theta_{\mathrm{mp}}$ $162-163^{\circ} \mathrm{C} ; \mathrm{IR}(\mathrm{KBr}) v\left(\mathrm{~cm}^{-1}\right): 3456,2966,2934,2867,1629,1456$, 1400, 1291, 1012, 973, 935, 864; ${ }^{1} \mathrm{H} \mathrm{NMR}\left(\mathrm{CDCl}_{3}\right) \delta: 0.721(\mathrm{~s}, 3 \mathrm{H}$, $\left.18-\mathrm{CH}_{3}\right), 0.837\left(\mathrm{~d}, 3 \mathrm{H}, \mathrm{J}=6.8,26-\mathrm{CH}_{3}\right.$ or $\left.27-\mathrm{CH}_{3}\right), 0.859(\mathrm{~d}, 3 \mathrm{H}$, $J=6.8,26-\mathrm{CH}_{3}$ or $\left.27-\mathrm{CH}_{3}\right), 0.869\left(\mathrm{t}, 3 \mathrm{H}, J=7.5,29-\mathrm{CH}_{3}\right), 0.936(\mathrm{~d}$, $\left.3 \mathrm{H}, \mathrm{J}=6.5,21-\mathrm{CH}_{3}\right), 1.124\left(\mathrm{~s}, 3 \mathrm{H}, 19-\mathrm{CH}_{3}\right), 2.284-2.243(\mathrm{~m}, 1 \mathrm{H}, 6-$ $\mathrm{CH}), 2.383-2.328(\mathrm{~m}, 2 \mathrm{H}, 2-\mathrm{CH}), 6.482(\mathrm{~s}, 1 \mathrm{H}, 4-\mathrm{CH})$.

\section{(3E,6E)-Dihydroximinocholest-4-ene (19a)}

Compound $5 \mathrm{a}(80 \mathrm{mg}, 0.2 \mathrm{mmol})$ was dissolved in $10 \mathrm{~mL}$ of $95 \% \mathrm{CH}_{3} \mathrm{CH}_{2} \mathrm{OH}$. After the mixture was heated to $60^{\circ} \mathrm{C}$, $\mathrm{CH}_{3} \mathrm{COONa} \cdot 3 \mathrm{H}_{2} \mathrm{O}(54 \mathrm{mg}, 0.4 \mathrm{mmol})$ and $\mathrm{NH}_{2} \mathrm{OH} \cdot \mathrm{HCl}(42 \mathrm{mg}$, $0.6 \mathrm{mmol}$ ) were added. The mixture was stirred for $1 \mathrm{~h}$ at $60^{\circ} \mathrm{C}$. Then the reaction was terminated and the majority of solvent was evaporated under reduced pressure. Proper water was added into the reaction mixture, and the product was extracted with ethyl acetate $(3 \times 20 \mathrm{~mL})$. The combined extracts were washed with saturated brine, dried with anhydrous sodium sulfate, and evaporated under reduced pressure. The residue was subjected to recrystallize in methanol to give $82 \mathrm{mg}$ of $19 \mathrm{a}(96.4 \%)$ as pale yellow crystals, $\theta_{\mathrm{mp}}$ $141-142^{\circ} \mathrm{C} . \mathrm{IR}(\mathrm{KBr}) \vee\left(\mathrm{cm}^{-1}\right): 3554,3178,3039,2941,2864$, 1634, 1458, 1376, 1307, 1000, 792; ${ }^{1} \mathrm{H} \mathrm{NMR}\left(\mathrm{CDCl}_{3}\right) \delta: 0.709(\mathrm{~s}$, $\left.3 \mathrm{H}, 18-\mathrm{CH}_{3}\right), 0.885\left(\mathrm{~d}, 3 \mathrm{H}, \mathrm{J}=6.5,26-\mathrm{CH}_{3}\right.$ or $\left.27-\mathrm{CH}_{3}\right), 0.889(\mathrm{~d}$, $3 \mathrm{H}, J=6.5,26-\mathrm{CH}_{3}$ or $\left.27-\mathrm{CH}_{3}\right), 0.936\left(\mathrm{~d}, 3 \mathrm{H}, J=6.4,21-\mathrm{CH}_{3}\right)$, 1.051(s, 3H, 19- $\left.\mathrm{CH}_{3}\right), 3.103\left(\mathrm{~d}, 1 \mathrm{H}, J=17.6, \mathrm{C}_{2}-\alpha \mathrm{H}\right), 3.353(\mathrm{dd}$, $\left.1 \mathrm{H}, J=15.6,4.3, \mathrm{C}_{7-\beta} \mathrm{H}\right), 6.544(\mathrm{~s}, 1 \mathrm{H}, 4-\mathrm{CH}), 6.780(\mathrm{~s}, 1 \mathrm{H}, 6-$ $\mathrm{NOH}), 6.948(\mathrm{~s}, 1 \mathrm{H}, 3-\mathrm{NOH}) ;{ }^{13} \mathrm{C} \mathrm{NMR}\left(\mathrm{CDCl}_{3}\right) \delta: 157.3(6-\mathrm{C})$, 156.8(3-C), 147.8(5-C), 119.3(4-C), 56.7(14-C), 56.1(17-C), 51.4(9C), 42.6(13-C), 39.5(7-C), 39.4(24-C), 38.3(12-C), 36.1(22-C), 35.7 (20-C), 33.6(1-C), 33.0(10-C), 29.6(8-C), 28.1(16-C), 28.0(25-C), 24.1(23-C), 23.8(15-C), 22.8(26-C), 22.5(27-C), 21.3(11-C), 18.5(21C), 17.6(2-C), 17.5(19-C), 11.9(18-C).

\section{4,22-dien (19b)}

(3E,6E)-Dihydroximino-24-ethylcholest-

Yield 98\%, $\theta_{\mathrm{mp}} 140-141^{\circ} \mathrm{C}$; $\mathrm{IR}(\mathrm{KBr}) v\left(\mathrm{~cm}^{-1}\right): 3317,2953,2864$, 1629, 1454, 1376, 1298, 1176, 959; ${ }^{1} \mathrm{H} \mathrm{NMR}\left(\mathrm{CDCl}_{3}\right) \delta: 0.731(\mathrm{~s}$, $\left.3 \mathrm{H}, 18-\mathrm{CH}_{3}\right), 0.826\left(\mathrm{~d}, 3 \mathrm{H}, \mathrm{J}=6.3,26-\mathrm{CH}_{3}\right.$ or $\left.27-\mathrm{CH}_{3}\right), 0.876(\mathrm{~d}$, $3 \mathrm{H}, J=6.3,26-\mathrm{CH}_{3}$ or $\left.27-\mathrm{CH}_{3}\right), 0.833\left(\mathrm{t}, 3 \mathrm{H}, J=7.0,29-\mathrm{CH}_{3}\right)$, $1.026\left(\mathrm{~s}, 3 \mathrm{H}, 19-\mathrm{CH}_{3}\right), 1.047\left(\mathrm{~d}, 3 \mathrm{H}, \mathrm{J}=6.0,21-\mathrm{CH}_{3}\right), 2.222-2.148(\mathrm{~m}$, $1 \mathrm{H}, 7-\mathrm{C} \alpha \mathrm{H}), 2.436-2.407\left(\mathrm{~m}, 1 \mathrm{H}, 2-\mathrm{C}_{\beta} \mathrm{H}\right), 3.101(\mathrm{dd}, 1 \mathrm{H}, J=14.9$,
2.5, $C_{2}-\alpha H$ ), 3.369(ddd, $\left.1 \mathrm{H}, J=17.5,15.0,4.5,7-\mathrm{C}_{\beta} \mathrm{H}\right), 5.057(\mathrm{dd}$, $1 \mathrm{H}, J=15.1,8.7,22-\mathrm{CH}), 5.179$ (dd, $1 \mathrm{H}, J=15.1,8.6,23-\mathrm{CH})$, 6.528(s, $1 \mathrm{H}, 4-\mathrm{CH}), 6.961(-\mathrm{OH}) ;{ }^{13} \mathrm{C} \mathrm{NMR}\left(\mathrm{CDCl}_{3}\right) \delta$ : 157.2(6C), 156.6(3-C), 147.6(5-C), 138.1(22-C), 129.6(23-C), 119.3(4-C), 56.8 (14-C), 55.9(17-C), 51.4(9-C), 51.3(24-C), 42.5(10-C), 40.4(13C), 39.4(20-C), 38.4(12-C), 33.7(25-C), 33.1(8-C), 31.9(1-C), 29.7(16-C), 28.8(2-C), 25.4(7-C), 24.2(28-C), 21.3(15-C), 21.2 (21C), 21.1(11-C), 19.1(27-C), 18.6(19-C), 17.6(26-C), 12.3(18-C), $12.2(29-\mathrm{C})$.

(3E,6E)-Dihydroximino-24-ethylcholest-4-en (19c)

Yield 93\%, $\theta_{\mathrm{mp}} 207-208^{\circ} \mathrm{C}$; IR(KBr) $v\left(\mathrm{~cm}^{-1}\right): 3542,3340,3061$, 2964, 2861, 1642, 1455, 1377, 1307, 1275, 1175, 1005, 956; ${ }^{1} \mathrm{H}$ $\mathrm{NMR}\left(\mathrm{CDCl}_{3}\right) \delta: 0.721\left(\mathrm{~s}, 3 \mathrm{H}, 18-\mathrm{CH}_{3}\right), 0.846\left(\mathrm{~d}, 3 \mathrm{H}, \mathrm{J}=7.0,26-\mathrm{CH}_{3}\right.$ or $\left.27-\mathrm{CH}_{3}\right), 0.867\left(\mathrm{~d}, 3 \mathrm{H}, \mathrm{J}=7.0,26-\mathrm{CH}_{3}\right.$ or $\left.27-\mathrm{CH}_{3}\right), 0.877(\mathrm{t}, 3 \mathrm{H}$, $\left.J=8.0,29-\mathrm{CH}_{3}\right), 0.951\left(\mathrm{~d}, 3 \mathrm{H}, \mathrm{J}=6.0,21-\mathrm{CH}_{3}\right), 1.034\left(\mathrm{~s}, 3 \mathrm{H}, 19-\mathrm{CH}_{3}\right)$, 2.227-2.152(m, 1H, 7-C $\alpha \mathrm{H}), 2.436-2.402\left(\mathrm{~m}, 1 \mathrm{H}, 2-\mathrm{C}_{\beta} \mathrm{H}\right), 3.111(\mathrm{dd}$, $1 \mathrm{H}, \mathrm{J}=16.5,2.0,2-\mathrm{C} \alpha \mathrm{H}), 3.382\left(\mathrm{ddd}, 1 \mathrm{H}, J=17.0,15.0,4.5,7-\mathrm{C}_{\beta} \mathrm{H}\right)$, 6.532(s, $1 \mathrm{H}, 4-\mathrm{CH}), 6.963(\mathrm{~N}-\mathrm{OH}) ;{ }^{13} \mathrm{C} \mathrm{NMR}\left(\mathrm{CDCl}_{3}\right) \delta: 157.3(\mathrm{C}-6)$, 156.7(3-C), 147.7(5-C), 119.3(4-C), 56.7(14-C), 56.1(17-C), 51.4(9C), 45.9(24-C), 42.6(10-C), 39.5(13-C), 38.4(12-C), 36.1(20-C), 34.0(22-C), 33.7(8-C), 33.1(1-C), 29.6(25-C), 29.3(16-C), 28.1(2-C), 26.2(7-C), 24.1(23-C), 23.1(15-C), 21.3(28-C), 19.8(11-C), 19.1(27C), 18.7(19-C), 18.5(26-C), 17.6(21-C), 12.0(29-C), 11.9(18-C).

(3E)-Hydroximinocholest-4-en- $6 \alpha$-ol (20)

$\mathrm{NaBH}_{4}(19 \mathrm{mg}, 0.28 \mathrm{mmol})$ was added to a solution of $3(140 \mathrm{mg}$, $0.339 \mathrm{mmol})$ and $\mathrm{CeCl}_{3} .7 \mathrm{H}_{2} \mathrm{O}(126 \mathrm{mg}, 0.339 \mathrm{mmol})$ in $\mathrm{CH}_{3} \mathrm{OH}$ $(20 \mathrm{~mL})$ in the interval of $5 \mathrm{~min}$ at room temperature. After $30 \mathrm{~min}$, the reaction was terminated. The solution was neutralized with $1 \mathrm{M} \mathrm{HCl}$. After evaporation of the majority of the $\mathrm{MeOH}$ under reduced pressure, ethyl acetate $(30 \mathrm{~mL})$ was added to the residue. The resulting solution was washed with cold water and saturated brines. After drying over anhydrous sodium sulfate, the solvent was removed under reduced pressure, and the resulting crude product was purified by chromatography. The 20 was obtained as pale yellow crystals $(115 \mathrm{mg}, 82 \%), \theta_{\mathrm{mp}} 172-173^{\circ} \mathrm{C}$; $\operatorname{IR}(\mathrm{KBr}) v\left(\mathrm{~cm}^{-1}\right): 3374$, $3043,2933,2905,2872,1629,1462,1376,1315,1287,1154$, 1123, 1074, 972, 886, 849; ${ }^{1} \mathrm{H} \mathrm{NMR}\left(\mathrm{CDCl}_{3}\right) \delta: 0.704(\mathrm{~s}, 3 \mathrm{H}, 18-$ $\left.\mathrm{CH}_{3}\right), 0.877\left(\mathrm{~d}, 3 \mathrm{H}, \mathrm{J}=2.0,26\right.$ or $\left.27-\mathrm{CH}_{3}\right), 0.890(\mathrm{~d}, 3 \mathrm{H}, \mathrm{J}=2.0$, 26 or $\left.27-\mathrm{CH}_{3}\right), 0.923\left(\mathrm{~d}, 3 \mathrm{H}, \mathrm{J}=6.5,21-\mathrm{CH}_{3}\right), 1.044(\mathrm{~s}, 3 \mathrm{H}, 19-$ $\left.\mathrm{CH}_{3}\right), 2.153-2.089\left(\mathrm{~m}, 1 \mathrm{H}, 2-\mathrm{C}_{\beta} \mathrm{H}\right), 3.026(\mathrm{ddd}, 1 \mathrm{H}, \mathrm{J}=13.6,6.8$, 3.5, 2-C $\alpha \mathrm{H}), 4.243\left(\mathrm{dd}, 1 \mathrm{H}, J=14.5,3.5,6-\mathrm{C}_{\beta} \mathrm{H}\right), 6.233(\mathrm{~s}, 1 \mathrm{H}$, $4-\mathrm{CH}) ;{ }^{13} \mathrm{C} \mathrm{NMR}\left(\mathrm{CDCl}_{3}\right) \quad \delta: 157.0(5-\mathrm{C}), 156.9(3-\mathrm{C}), 113.8(4-\mathrm{C})$, 68.9(6-C), 56.3(17-C), 55.8(14-C), 53.6(9-C), 42.5(13-C), 41.2(10C), 39.7(24-C), 39.5(12-C), 38.5(7-C), 36.2 (22-C), 35.8(20-C), 35.2(1-C), 34.3(8-C), 28.2(2-C), 28.1(25-C), 28.0(16-C), 24.3(15-C), 23.9(23-C), 22.8(26-C), 22.6(27-C), 21.4(11-C), 18.7(19-C), 18.6(21C), $12.0(18-C)$.

\section{Antiproliferative activity}

Materials and methods

Stock solutions of compounds 1, 2 and 4, were prepared in sterile dimethyl sulfoxide (DMSO) (Sigma) at a concentration of $10 \mathrm{mg} / \mathrm{mL}$ and afterwards diluted with complete nutrient medium (RPMI-1640) supplemented with $10 \%$ heat inactivated fetal bovine serum and $0.1 \mathrm{~g} / \mathrm{L}$ penicillin $\mathrm{G}+0.1 \mathrm{~g} / \mathrm{L}$ streptomycin sulfate. 


\section{Cell culture}

Sk-Hep-1, H-292, PC-3 (ATCC) and Hey-1B (A gift from Dr. Yan $\mathrm{Xu}$, University of Indiana) cells were cultured in a proper medium supplemented with $10 \%$ fetal bovine serum in a humidified atmosphere of $5 \% \mathrm{CO}_{2}$ at $37^{\circ} \mathrm{C}$.

\section{Treatment of cancer cells}

Cancer cells $\left(4 \times 10^{3}\right.$ cells $\left./ 200 \mu \mathrm{L}\right)$ were seeded into each well of a 96-well microtiter plate. After incuation for $24 \mathrm{~h}$, the compounds with a series of concentrations (range $20-80 \mu \mathrm{g} / \mathrm{mL}$ ) were added to the cells. An equal amount of DMSO was added to the cells used as negative controls. All were treated in triplicate.

\section{Determination of cell viability}

MT stetrazolium salt (3-(4,5-dimethylthiazol-2-yl)-5-(3carboxymethoxyphenyl)-2- (4-sulfophenyl)-2H-tetrazolium) (CellTiter 96 AQueous Non-Radioactive Cell Proliferation Assay, Cat.\# G5421, Promega Corporation) dye reduction assay was used. The assay is dependent on the MTS being reduced to an aqueous, soluble formazan by dehydrogenase enzymes found in metabolically active cells. The quantity of formazan product as measured by the amount of $490 \mathrm{~nm}$ absorbance is directly proportional to the number of living cells in culture. Briefly, after treatment (see Section 4.2.3) for $72 \mathrm{~h}$, the medium was removed and the cells were incubated with $100 \mu \mathrm{L}$ of fresh medium plus $20 \mu \mathrm{L}$ of MTS solution according to the instruction provided by the manufacturer for additional $4 \mathrm{~h}$. The absorbance (A) at $490 \mathrm{~nm}$ was measured using an Beckman coulter LD400 AD/LD analysis spectrometer. IC 50 concentration was defined as the concentration of an agent inhibiting cell survival by $50 \%$, compared to a control.

\section{Acknowledgments}

The authors acknowledge the financial support of the National Natural Science Foundation of China (Project: 20562001), the Natural Science Foundation of Guangxi Province (Guike: 057554).

\section{REFERENCES}

[1] Blunt JW, Copp BR, Hu WP, Munro MHG, Northcote PT, Prinsep MP. Marine natural products. Nat Prod Rep 2007;24:31-86.

[2] Blunt JW, Copp BR, Munro MHG, Northcote PT, Prinsep MP. Marine natural products. Nat Prod Rep 2005;22:15-61.

[3] Faulkner DJ. Marine natural product. Nat Prod Rep 2001;18:1-49.

[4] Jaime R, Lucia N, Solange P, Carlos J. Isolation and synthesis of the first natural 6-hydroximino-4-en-3-one steroids from the sponges cinachyrella spp. Tetrahedron Lett 1997;38: 1833.

[5] Xiao DJ, Peng XD, Deng SZ, Ma WZ, Wu HM. Structure elucidation of (3E)-cholest-4-en-3,6-dione-3-oxime in marine sponge Cinachyrella australiensis from the south china sea. Chin J Org Chem 2005;25(12):1606-9.

[6] Deive N, Rodriľguez J, Jimeinnez C. Synthesis of cytotoxic 6E-hydroximino-4-ene steroids: structure/activity studies. J Med Chem 2001;44:2612-8.

[7] Jindal DP, Chattopadhaya R, Guleria S, Gupta R. Synthesis and antineoplastic activity of 2-alkylaminoethyl derivatives of various steroidal oximes. Euro J Med Chem 2003;38:1025-34.

[8] Krstića NM, Bjelaković MS, Zižakb Z, Pavlovic MD, Juraníc ZD, Pavlovíc VD. Synthesis of some steroidal oximes, lactams, thiolactams and their antitumor activities. Steroids 2007;72:406-14

[9] Poza J, Rega M, Paz V, Alonso B, Rodríguez J, Salvador N, et al. Synthesis and evaluation of new 6-hydroximinosteroid analogues as cytotoxic agents. Bioorg Med Chem 2007;15:4722-40.

[10] JianGuo Cui, Liliang Huang, Lei Fan, Aimin Zhou. A facile and efficient synthesis of some (6E)-hydroximino-4-en-3-one steroids, steroidal oximes from Cinachyrella spp. Sponges. Steroids 2008;73(3): 252-6. 